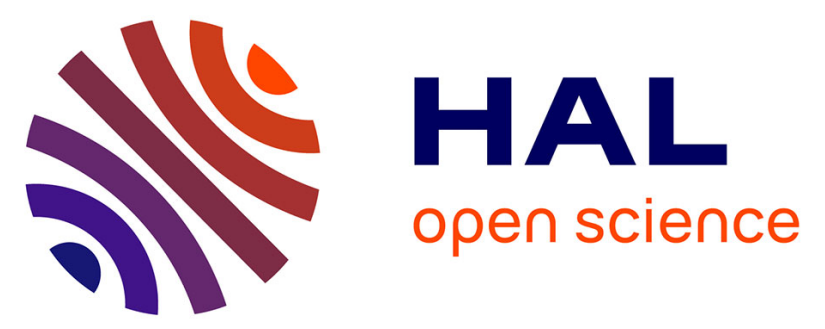

\title{
Influence of the Polyacrylic Acid Binder Neutralization Degree on the Initial Electrochemical Behavior of a Silicon/Graphite Electrode
}

Jianhan Xiong, Nicolas Dupré, Driss Mazouzi, Dominique Guyomard, Lionel Roué, Bernard Lestriez

\section{To cite this version:}

Jianhan Xiong, Nicolas Dupré, Driss Mazouzi, Dominique Guyomard, Lionel Roué, et al.. Influence of the Polyacrylic Acid Binder Neutralization Degree on the Initial Electrochemical Behavior of a Silicon/Graphite Electrode. ACS Applied Materials \& Interfaces, 2021, 13 (24), pp.28304-28323. 10.1021/acsami.1c06683 . hal-03287954

\section{HAL Id: hal-03287954 https://hal.science/hal-03287954}

Submitted on 19 Jul 2021

HAL is a multi-disciplinary open access archive for the deposit and dissemination of scientific research documents, whether they are published or not. The documents may come from teaching and research institutions in France or abroad, or from public or private research centers.
L'archive ouverte pluridisciplinaire HAL, est destinée au dépôt et à la diffusion de documents scientifiques de niveau recherche, publiés ou non, émanant des établissements d'enseignement et de recherche français ou étrangers, des laboratoires publics ou privés. 


\section{Influence of the polyacrylic acid binder}

\section{neutralization degree on the initial electrochemical}

\section{behavior of a silicon/graphite electrode}

AUTHOR NAMES

Jianhan Xiong, ${ }^{1}$ Nicolas Dupré, ${ }^{1}$ Driss Mazouzi, ${ }^{2}$ Dominique Guyomard, ${ }^{1}$ Lionel Roué, ${ }^{3}$ Bernard Lestriez $^{1 *}$

AUTHOR ADDRESS

${ }^{1}$ Université de Nantes, CNRS, Institut des Matériaux Jean Rouxel, IMN, F-44000 Nantes,

France

${ }^{2}$ Sidi Mohamed Ben Abdellah University, Materials, Natural Substances, Environment and Modeling Laboratory. Multidisciplinary Faculty of Taza. B.P.: 1223 Taza-Gare, Fes, Morocco 30000.

${ }^{3}$ Institut National de la Recherche Scientifique (INRS), Centre Énergie, Matériaux, Télécommunications (EMT), 1650, Boulevard Lionel Boulet, Varennes, QC J3X 1S2, Canada.

KEYWORDS 
Lithium-ion batteries, poly(acrylic acid) binder, silicon/graphite negative electrode, solidelectrolyte interphase, current collector, corrosion, slurry, rheological properties

\section{ABSTRACT}

The role of the physico-chemical properties of the water soluble PAA binder on the lithium electrochemical performance of highly loaded silicon/graphite 50/50 wt\% negative electrodes has been examined as a function of the neutralization degree $\mathrm{x}$ in $\mathrm{PAAH}_{1-\mathrm{x}} \mathrm{Li}_{\mathrm{x}}$ at initial cycle in an electrolyte not-containing ethylene carbonate. Electrode processing in acidic PAAH binder at pH 2.5 leads to a deep copper corrosion resulting in a significant electrode cohesion and adhesion to the current collector surface, but the strong binder rigidity may explain the big cracks occurring at the electrode surface at first cycle. The non-uniform binder coating on the materials surface leads to an important degradation of the electrolyte explaining the lowest initial coulombic efficiency and the lowest reversible capacity among the studied electrodes. When processed in neutral $\mathrm{pH}$, the $\mathrm{PAAH}_{0.22} \mathrm{Li}_{0.78}$ binder forms a conformal artificial SEI layer on the materials surface, which minimizes the electrolyte reduction at first cycle and then maximizes the initial coulombic efficiency. However, the low mechanical resistance of the electrode and its strong cracking explain its low reversible capacity. Electrodes prepared at intermediate $\mathrm{pH} 4$ combine the positive assets of electrodes prepared at acidic and neutral $\mathrm{pH}$. They lead to the best initial performance with a notable areal capacity of $7.2 \mathrm{mAh} \mathrm{cm}^{-2}$ and the highest initial coulombic efficiency at around 90\%, a value much larger than the usual range reported for silicon/graphite anodes. All data obtained with complementary characterization techniques were discussed as a function of the PAA polymeric chain molecular conformation, microstructure, and surface 
adsorption or grafting, emphasizing the tremendous role of the binder on the electrode initial performance.

\section{INTRODUCTION}

In response to the demand of higher-energy LIB and subsequent EVs with higher autonomy, silicon has attracted a lot of attentions as one of the most promising candidates for anode material application. ${ }^{1-4}$ Theoretically, silicon offers a gravimetric capacity 10 times higher than a conventional graphite anode $\left(\mathrm{Li}_{15} \mathrm{Si}_{4} 3579 \mathrm{mAh} \mathrm{g}^{-1}\right.$ vs. $\left.\mathrm{LiC}_{6} 372 \mathrm{mAh} \mathrm{g}^{-1}\right)$ and 3 times over the graphite in volumetric capacity $\left(2154 \mathrm{mAh} \mathrm{cm}^{-3}\right.$ vs. $\left.738 \mathrm{mAh} \mathrm{cm}^{-3}\right){ }^{3}$ However, the application of silicon-based electrode will remain hampered if the following difficulties are not overcome: a) Dramatic volumetric expansion up to $280 \%$ results in particles pulverization due to high mechanical stress, but it can be resolved when a critical nanoparticle size is respected., Nonetheless, nanosizing the materials leads to more electrolyte degradation due to a higher specific surface developed and requires more binder and eventually more conducting additive in the electrode formulation; ${ }^{6}$ b) Repeated volumetric changes during silicon (de-)alloying process deteriorate the electrode integrity, causing microcracks formation and electrical insulation of active materials islands; ${ }^{7,8}$ c) The instability of solid electrolyte interphase (SEI) layer as a result of repetitive expansion and contraction leads to continuously electrolyte decomposition on fresh silicon surface which consumes irreversibly the limited lithium inventory. ${ }^{2}$ This also hampers the electrochemical reaction, and once the SEI on the particles becomes too thick, the electrode capacity decline occurs; this problem could be overcome via the optimization of the electrolyte composition. For instance, fluoroethylene carbonate (FEC) is an additive which is recommended 
to be added into the electrolyte for the improvement of Si-based electrodes' cyclability. 9,10 However, it consumes during cycling and the end of life of Li-ion cells coincides with its total consumption. $^{11}$

One of the remedies is to combine silicon with graphite $(\mathrm{Gr})$ regarding the issue of the large swelling of the silicon-based electrode. Since graphite only expands by $12 \%$ at full lithiation, blending Si with Gr can thus attenuate the severe volumetric variations and helps maintaining electronic conduction through the electrode. ${ }^{12}$ One shall distinguish the blending of silicon with graphite, from the synthesis of silicon-graphite composites. The first approach has the advantage of being simple, inexpensive and easily scalable. ${ }^{13}$

The formulation of the electrodes must also be adapted to the problem of variation in volume of the Si or Si/Gr electrodes. ${ }^{14-16}$ Numerous studies have shown that the selection of the binder is crucial and should be particularly adressed. ${ }^{11,14,17-19}$ This one appears not only essential to constrain the volume expansion of the electrode or maintain contact with the current collector, but also to minimize the degradation of the liquid electrolyte by pre-forming an "artificial" protective SEI layer. ${ }^{11,14,20,21}$ The preparation and processing of the electrode slurry (e.g. type of grinding, casting speed, drying temperature) and electrode parameters (porosity ${ }^{22-24}$ and thickness ${ }^{25}$ ) are also critical to the electrochemical behavior of the electrode.

The sodium salt of carboxymethylcellulose (CMC) and polyacrylic acid (PAA) are the most studied polymer binders for Si- or Si/Gr-based electrodes thanks to the following advantages: a) absence of swelling in the electrolyte, b) interactions or strong bonds with the silicon surface thanks to the carboxylate/carboxylic acid (and hydroxyl in CMC) groups, which make them superior to PVdF for the mechanical strength of the electrode, and also, c) eco-friendly and low cost, as these water soluble polymers enable to manufacture the electrode in aqueous media. ${ }^{19,26-}$ 
${ }^{28} \mathrm{CMC}$ in combination with an elastomer latex (styrene-butadiene rubber, SBR) is the standard binder for Gr electrodes. For Si or Si/Gr based electrodes, PAA is increasingly preferred over CMC because of its better electrochemical performance, ${ }^{26,29}$ as well as the facility to modulate the neutralization degree $\mathrm{x}$ in $\mathrm{PAAH}_{1-\mathrm{x}} \mathrm{Li}_{\mathrm{x}}$, which makes it possible to develop several formulation possibilities. ${ }^{29-32}$ Indeed, this neutralization degree considerably affects the viscosity and the $\mathrm{pH}$ of the binder solution, and consequently it modifies the characteristics of the electrode slurry such as its rheological properties and its homogeneity. ${ }^{33-35}$ Moreover, modulating the $\mathrm{pH}$ of aqueous Si-based electrode slurries is very important to avoid the hydrolysis of elemental silicon that produces flammable hydrogen gas $\left(\mathrm{Si}+2 \mathrm{H}_{2} \mathrm{O} \rightarrow \mathrm{SiO}_{2}+\mathrm{H}_{2}\right)$, which raises safety and quality concerns on large-scale electrode fabrication lines. This detrimental reaction is much less pronounced at acidic $\mathrm{pH} \cdot{ }^{36,37}$

In the case of Si/Gr blend electrodes with higher content of Gr than Si (from Si:Gr 17:83 to 37.5:62.5 wt\%), lots of works reported better electrochemical performance was obtained for $\mathrm{PAAH}_{0.2} \mathrm{Na}_{0.8} 21,30,35,38,39$ or PAALi ${ }^{31,32}$ compared to PAAH, i.e. for electrode slurries prepared in neutral $\mathrm{pH}$ condition. It was nevertheless not clear whether the performance enhancement was due to a more homogeneous dispersion of active materials in the composite electrode and a more uniform electrode coating, thanks to more adapted rheological properties, or due to the superior ability of the binder to perform as an artificial SEI. It is, indeed, worth to mention the superior ability of PAANa or PAALi performing as a preformed SEI over PAAH. ${ }^{21,29,31,39-41}$ In the former case, after the electrode manufacturing, a thin layer of these binders is uniformly covering at the surface of the Si and Gr particles as an artificial SEI, which minimizes the direct contact with the electrolyte and its subsequent reduction at least for the first cycle. ${ }^{21}$ In addition, the drawback of the acidic form of a binder, such as PAAH, is that carboxylic acid groups can be electrochemically 
reduced and converted to lithium carboxylates..$^{29,41}$ The protons that are released are prone to accelerate the decomposition of $\mathrm{LiPF}_{6}$ compared to $\mathrm{CMC}^{41}$

In opposite with above studies, Hu et al. found for both Si/Gr (17:83 wt\%)-based half- and full-cells consistently decreasing electrochemical performance with increasing the neutralization degree, from PAAH to PAALi. ${ }^{34}$ Hays et al. also reported a much higher adhesion for PAAHbased Si/Gr electrodes compared to PAALi-based ones. ${ }^{31}$ Contradictions between different studies may result from differences in the electrode manufacturing process (mixing and drying conditions), ${ }^{42}$ the characteristics of the active material (particle size, silicon surface chemistry, silicon/graphite ratio), ${ }^{33,43}$ or the molar mass of the binder, ${ }^{44}$ as well as the cycling conditions and in particular the choice of electrolyte. This great diversity makes the rationalization difficult and highlights the need to understand and rationalize the underlying phenomena.

The peculiarities of the present work compared to previous ones (see Table S1 and Figure S1) are devoted to the $\mathrm{Si} / \mathrm{Gr}$ electrodes richer in silicon (Si/Gr 50:50) and much more loaded to meet the energy density target of the automotive industry (practical areal capacity about $6 \mathrm{mAh} \mathrm{cm}^{-2}$ ), as well as using a low cost silicon with straightforward and easy-to-scale-up synthesis, and performing the cycling in an electrolyte without ethylene carbonate (EC). Indeed, EC, which enables operation of both the negative and positive commercial electrodes, is generally considered as an essential co-solvent. Its high permittivity is essential to solubilize the $\mathrm{LiPF}_{6}$ salt. However, for silicon-based electrodes, the continuous reduction of EC at low potential results in massive accumulation of degradation products at the active mass surface and in the pores of the composite electrode, inhibiting the lithium transport and transfer. ${ }^{45,46}$ Recent studies show it is possible to cycle full Li-ion cells by totally removing EC from typical organic carbonate-based electrolyte and achieve satisfactory or even better cyclability. ${ }^{47,48}$ Here, we have substituted EC 
with fluoroethylene carbonate (FEC), a high permittivity solvent the addition of which as an additive is mandatory for the cycling of negative silicon-based electrodes. The electrodes are prepared in neutralized PAA solution fixed at $\mathrm{pH} 2.5,4$ and 6, corresponding to PAAH, $\mathrm{PAAH}_{0.85} \mathrm{Li}_{0.15}$ and $\mathrm{PAAH}_{0.22} \mathrm{Li}_{0.78}$ binder compositions. Noteworthy, the quantity of water used to manufacture the slurry is adjusted with respect to the neutralization degree of the binder, in order to cancel out the differences in rheological properties and to obtain as much as possible identical electrode morphologies in terms of the distribution of the silicon and graphite particles. At micrometric scale, this adjustment is expected to enable more direct links between the electrochemical performance and the binder conformation at the molecular scale. Prior to cycling, the critical interfacial interaction between the electrode and the current collector are scrutinized by SEM imaging, SEM-EDX and XPS analysis. The mechanical properties of electrodes are evaluated thanks to the scratch test. Then, the electrodes are characterized before and after one full cycle by SEM imaging, EIS and MAS NMR spectroscopies in order to offer a deep understanding of the morphological and electrochemical mechanisms at initial cycling. Lastly, the electrochemical cycling of $\mathrm{pH}$-adjusted electrodes is carried out until 40 cycles. As a result, this work revealed the best cyclability when the $\mathrm{Si} / \mathrm{Gr}$ electrode is obtained with the $\mathrm{PAAH}_{0.85} \mathrm{Li}_{0.15}$, i.e. prepared in slightly acidic conditions.

\section{EXPERIMENTAL SECTION}

Materials. - A blend of silicon and graphite (Si/Gr) was used as active material. The silicon powder used in the present study was obtained by milling a millimetric powder (99.96 \% Si, 325 mesh, Materion), with a high-energy miller (Union Process attritor HD-01) with a ball-topowder mass ratio of 10:1 at $600 \mathrm{rmp}$ for 20 hours under argon atmosphere. The as-milled Si 
powder is nanostructured with micrometric agglomerates $\left(D_{\mathrm{v} 50}=9.4 \mu \mathrm{m}, \mathrm{S}_{\mathrm{BET}}=21 \pm 1 \mathrm{~m}^{2} \mathrm{~g}^{-1}\right)$. The graphite here is SFG6 from Timcal Timrex. GM15 (xGnP Graphene Nanoplatelets Grade M, thickness $\sim 6-8 \mathrm{~nm}, \mathrm{D}_{\text {avg }}=15 \mu \mathrm{m}$, XG Sciences) was used as a conductive additive. The selected binder was the polyacrylic acid (PAA) from Sigma-Aldrich $\left(\mathrm{Mw} \sim 450 \mathrm{~kg} \mathrm{~mol}^{-1}\right)$. It was used in non or partially neutralized state, by adding $\mathrm{LiOH} . \mathrm{H}_{2} \mathrm{O}$ salt (Sigma-Aldrich, white crystal), which is specified in the next section. The water used was ultrapure $\left.(<0.05 \mu \mathrm{S} \mathrm{cm})^{-1}\right)$.

Electrode preparation. - The PAA binder is very hygroscopic and its use requires a predrying process for $3 \mathrm{~h}$ at $95{ }^{\circ} \mathrm{C}$ under vacuum to remove the adsorbed water. Before preparing the electrode slurries, the binder solution $(\mathrm{PAA}+(\mathrm{LiOH})+$ water $)$ was stirred for at least 5 hours to reach the $\mathrm{pH}$ stabilization since the acid-base reaction $\mathrm{PAAH}+\mathrm{LiOH} \rightarrow \mathrm{PAALi}+\mathrm{H}_{2} \mathrm{O}$ is a slow process. The $\mathrm{pH}$ of PAA solution after the dissolution was stabilized at 2.5, or 4, or 6 depending on the amount of $\mathrm{LiOH}$ added, corresponding to a neutralization degree $\mathrm{x}$ of $0,0.15$ and 0.78 in $\mathrm{PAAH}_{1-\mathrm{x}} \mathrm{Li}_{\mathrm{x}}$. The electrode slurries were obtained by a total solid content of $400 \mathrm{mg}$ comprising Si, Gr, GM15, and PAA (or partially neutralized PAA) pre-dissolved solution with additional deionized water (see Figure 1b), which is milled through a Fritsch Pulverisette 7 mixer with 3 silicon nitride balls (9.5 mm diameter) at $500 \mathrm{rpm}$ for $1 \mathrm{~h}$. The slurry was afterward tape cast onto a $25 \mu \mathrm{m}$ thick copper foil (99.99\%, MTI) at a blade speed of $5 \mathrm{~mm} / \mathrm{s}$. The electrode film was firstly dried at room temperature with limited airflow for one night before being punched out into disks of $10 \mathrm{~mm}$ diameter. A further drying step for $2 \mathrm{~h}$ at $120^{\circ} \mathrm{C}$ under vacuum was done before battery assembly. The mass ratio of the electrode corresponds to $\mathrm{Si} / \mathrm{Gr} / \mathrm{GM} 15 / \mathrm{PAAH}_{1-\mathrm{x}} \mathrm{Li}_{\mathrm{x}}$ 43:43:4:10. The Si/Gr loading varies between 3.0-3.5 $\mathrm{mg} \mathrm{cm}^{-2}$. Their thickness and porosity are comprised between $45-55 \mu \mathrm{m}$ and 55-65\%, respectively. Theoretical specific capacity of as-made electrode is $1975 \mathrm{mAhg}^{-1}\left(5.9-6.9 \mathrm{mAh} \mathrm{cm}^{-2}\right)$. 
Slurry characterization. - The rheological studies of electrode slurries were performed on a controlled-stress rotating rheometer (Anton Paar, MCR 101). Measurements were taken at $25^{\circ} \mathrm{C}$ with a $50 \mathrm{~mm}$ diameter plane-and-plane geometry, and the gap between the sample and the geometry was set to $0.5 \mathrm{~mm}$. Two main rheological tests were carried out in order to simulate (i) the tape casting and (ii) the beginning of the electrode drying occurring upon electrode preparation. In the former case, the viscosity under continuous shear was measured at a rate sweep from 0.1 to $1000 \mathrm{rad} / \mathrm{s}$ then during a reverse sweep. For the latter case the G'(storage) and G” (loss) moduli were recorded every 5 seconds at an oscillation frequency of $1 \mathrm{~Hz}$ with an amplitude variation of $0.4 \%$ for 30 minutes. Note that before step (i) a continuous constant shear during 3 minutes followed by a rest of 5 minutes was carried out, to ensure that the slurries, which are viscoelastic materials and thus owning a rheological property depending on time, are in the same state.

Electrode mechanical characterization. - A scratch test was performed by a balanced beam scrape adhesion and mar tester (BYK-GARDNER) to evaluate the quality of the adhesion of the electrode on the copper current collector. Spit stylus was selected to scrape the electrode film at a speed of $5 \mathrm{~mm} / \mathrm{s}$ approximatively. The practical scrape load was considered to be the lowest load for which the underlying copper foil becomes visible. Each test was repeated at least three times.

Electrode microstructure characterization. - To visualize the microstructure at the surface of the electrodes as well as their interface with the current collector, SEM images were acquired using a high resolution scanning electron microscope JEOL JSM 7600F equipped with a field-emission gun operating at $2 \mathrm{kV}$. EDX quantifications were performed on a JEOL JSM 5800LV coupled with an energy-dispersive spectrometer SDD SAMx. To access the electrode interface we developed a simple method: the electrode and the current collector were separated by 
quickly tearing off adhesive tape after applying it on the electrode. The as-obtained electrode interface was later analyzed by SEM imaging, EDX spectroscopy and XPS spectroscopy.

XPS measurements were carried out with a Kratos Axis Nova spectrometer using a monochromatic $\mathrm{Al} \mathrm{K} \alpha$ source $(1486.6 \mathrm{eV})$ operating at $300 \mathrm{~W}$. The instrument base pressure was $5 \times 10^{-10}$ Torr. Sample analysis area was fixed to $700 \times 300 \mu \mathrm{m}$. Pass energy (PE) of $80 \mathrm{eV}$ corresponding to an all-over Fermi edge instrumental resolution of $0.89 \pm 0.02 \mathrm{eV}$ was used to acquire wide range survey spectra. A lower PE of $40 \mathrm{eV}$ was applied to acquire narrow spectra of the $\mathrm{C} 1 \mathrm{~s}, \mathrm{O}$ 1s, $\mathrm{Cu} 2$ 2pand Si 2p levels, corresponding to an all-over Fermi edge instrumental resolution of $0.55 \mathrm{eV}$. The charge compensation, operating with a low-energy electron gun, was used in the case of insulating samples. Acquired XPS spectra were fitted with CasaXPS software, using Gaussian/Lorentzian and LA (mostly for conductive materials) line shapes and Tougaard U3 background correction. Due to the high content of graphite in analyzed electrodes, C 1s spectra were calibrated with the C 1s main peak found at a binding energy of $284.4 \mathrm{eV}$ which is attributed to the $\mathrm{C}=\mathrm{C}$ bonding in graphite. Thus, the corresponding $\mathrm{C} 1 \mathrm{~s}$ peak for adventitious carbon is located at $285 \mathrm{eV}$. Si 2p spectra were normalized with respect to the height of the elementary silicon peak at $99.5 \mathrm{eV}$. Furthermore, $\mathrm{X}$-ray beam damage was observed for the samples containing copper ions. The $\mathrm{Cu} 2 \mathrm{p}$ spectrum showed a shift of the $\mathrm{Cu}^{2+}$ peak to lower binding energy after each spectrum acquisition, indicating a reduction of oxidized $\mathrm{Cu}^{2+}$ to metallic copper. The $\mathrm{Cu} 2 \mathrm{p}$ XPS data interpreted here correspond to the first survey acquisition, with a short acquisition time (180 s) to consider the sample degradation as negligible and leading to a constant amount of $\mathrm{Cu}^{2+}$ being reduced to $\mathrm{Cu}$ under the $\mathrm{X}$-ray beam. $\mathrm{Cu} 2 \mathrm{p}$ spectra were normalized with respect to the height of the metallic copper peak at $932.3 \mathrm{eV}$ when possible, or with respect to that of the main 
$\mathrm{Cu}^{2+}$ peak at $934.3 \mathrm{eV}$ when the metallic copper peak is too low because of its strong overlapping with the main $\mathrm{Cu}^{2+}$ peak.

Electrochemical measurements. - For cycling tests, half cells were assembled in a glove box under argon atmosphere using CR 2032 coin cell configuration. The oxygen and moisture in glovebox were maintained lower than $0.2 \mathrm{ppm}$. The Si/Gr electrode was set as working electrode and a lithium metal foil (0.7 mm thick, Sigma-Aldrich) as reference and counter electrode. A borosilicate glass-fiber (Whatman GF/D) and a polyolefin based (Celgard 2500) discs were used as separators and were soaked with a $200 \mu \mathrm{L}$ electrolyte consisting of $1 \mathrm{M} \mathrm{LiPF}_{6}$ in dimethyl carbonate(DMC)/fluoroethylene carbonate (FEC) 70/30 v/v. The crimping pressure applied to the cell was 0.6 ton (using a MSK-160D electric coin cell crimping machine). Electrodes were cycled with a VMP multichannel electrochemical potentiostat (Bio-Logic) in galvanostatic mode (GCPL) at a rate of $\mathrm{C} / 16.5$ during discharge and $\mathrm{C} / 8.3$ during charge at $25^{\circ} \mathrm{C}$, corresponding to current densities of $120 \mathrm{~mA} \mathrm{~g}^{-1}$ and $240 \mathrm{~mA} \mathrm{~g}^{-1}$ respectively. The potential window was $0.005-1 \mathrm{~V}$ versus $\mathrm{Li}^{+} / \mathrm{Li}$ allowing for a full capacity cycling. The specific capacity values are reported with respect to the total mass of active material $\mathrm{Si}$ and $\mathrm{Gr}$. The acquired data were analyzed by EC-Lab software. The given values in result section correspond to averaged data obtained from three different cells for each $\mathrm{pH}$.

To perform electrochemical impedance spectroscopy (EIS), a three-electrode configuration Swagelok ${ }^{\circledR}$ cell was used with lithium metal as reference and counter electrodes. The applied perturbation amplitude was $5 \mathrm{mV}$ and a $200 \mathrm{kHz}$ to $10 \mathrm{mHz}$ frequency range was scanned. The measurement was taken at various desired potentials after stabilization while a very low current I $<\mathrm{C} / 200$ was reached. Between two successive acquisitions, the cell was cycled in the same conditions as described above. EIS results were fitted with Zfit software, included in EC-Lab. 


\section{Magic Angle Spinning Nuclear Magnetic Resonance (MAS NMR) characterizations.}

- Electrodes were stopped at the end of charge (delithiation) for MAS NMR analysis. They were collected from the disassembled CR 2032 cells inside the glove box, rinsed with two drops of dimethyl carbonate (DMC) and dried under vacuum at $50^{\circ} \mathrm{C}$ for one night before being removed from the current collector. The resulting powder was then filled into a cylindrical $2.5 \mathrm{~mm}$ diameter zirconia rotor. ${ }^{7} \mathrm{Li}$ and ${ }^{19} \mathrm{~F}$ MAS NMR measurements were carried out on a Bruker advance-500 spectrometer $\left(\mathrm{B}_{0}=11.8 \mathrm{~T}\right.$, Larmor Frequency $\left.v_{0}\left({ }^{7} \mathrm{Li}\right)=194 \mathrm{MHz}, v_{0}\left({ }^{19} \mathrm{~F}\right)=470 \mathrm{MHz}\right)$. Spinning frequencies up to $25 \mathrm{kHz}$ were used. ${ }^{7} \mathrm{Li}$ NMR spectra were acquired with a single pulse sequence and a recycle time of $40 \mathrm{~s} .{ }^{19} \mathrm{~F}$ NMR spectra were acquired using a Hahn echo sequence to discard the significant contribution from the probe signal and a recycle time of $30 \mathrm{~s}$. Long recycle times were used to ensure quantitative measurements. All the spectra were normalized taking into account the number of scans, the receiver gain and the mass of the sample. ${ }^{7} \mathrm{Li}$ and ${ }^{19} \mathrm{~F}$ integrated intensities were determined by using spectral simulation Dmfit software, ${ }^{49}$ taking the spinning sidebands into account. The absolute quantification of detected species was performed using i) a numerical fit and integration of each set of peaks corresponding to a chemical species, ii) a calibration curve obtained from reference LiF-Si or -Si/Gr mixtures. ${ }^{50}$

\section{RESULTS AND DISCUSSIONS}

Rheological adjustment of the slurries. - The adjustment of the electrode slurry viscosity as a function of the PAA neutralization degree $\mathrm{x}$ in $\mathrm{PAAH}_{1-\mathrm{x}} \mathrm{Li}_{\mathrm{x}}$ appears crucial to maintain a stable and homogenous dispersion during electrode coating and throughout the drying process, especially on a large scale. ${ }^{34}$ Indeed, PAA carboxylic groups naturally associated through hydrogen bonds can be disassociated in solution due to the electrostatic repulsion between neighboring carboxylate 
groups with increasing PAA neutralization degree $\mathrm{x}$ (i.e. with increasing the solution $\mathrm{pH}$ ). This modification of PAA chains conformation results in a modification of the rheological properties and of the dispersion state of the electrode slurry. ${ }^{35,38}$ In the following, we have thus chosen to prepare electrode slurries with similar rheological properties whatever the PAA neutralization degree in order to reach a reproducible coating quality. ${ }^{51}$

The rheological properties of the three Si/Gr based electrode slurries with $\mathrm{pH}$ 2.5, 4 and 6 are reported in Figure 1a. The relationship between $\mathrm{x}$ in $\mathrm{PAAH}_{1-\mathrm{x}} \mathrm{Li}_{\mathrm{x}}$ and the $\mathrm{pH}$ of the binder solution is given in Figure S2. Using a similar silicon grade, Karkar et al. demonstrated that a high quality electrode film was obtained by tape casting when an optimized rheological behavior of the electrode slurry was respected, ${ }^{16}$ reported here as the dotted line in Figure 1a. The viscosity adjustments consist in a number of attempts to vary the amount of solvent quantities in order to achieve the same rheological properties for the electrode slurries with different neutralization degrees. Figure 1b indicates that the required water volume to be added to reach the targeted viscosity increases drastically as a function of the $\mathrm{pH}$, which corresponds to the reported decreasing solid content percentage. The results obtained for $\mathrm{pH} 3,5$ and 7 are added for comparison purpose and to give a sense to the observed trend. All the Si/Gr electrode slurries prepared here showed a shear-thinning behavior (pseudoplastic behavior) as viscosity decreases under shear strain. The viscosity of the slurry increases with the neutralization degree at equal solid mass loading. Due to hydrogen bonds between neighboring carboxylic groups at the natural $\mathrm{pH}$ (2.5) of a PAAH solution, folding of the PAAH chains occurs yielding a low viscosity. On the contrary, when the polymer is deprotonated, the electrostatic repulsion occurring between neighboring carboxylate groups promotes polymer-solvent interactions, which leads to an 
unfolding mechanism of the chains, and a subsequent rise in viscosity. ${ }^{33,52}$ Therefore, an increased amount of water is needed at higher $\mathrm{pH}$ to keep the same viscosity with increasing $\mathrm{pH}$.

Rheological properties similar to those of a soft gel are targeted for the electrode slurry at zero shear rate (i.e. under rest), in order to avoid agglomeration and/or sedimentation after casting on the current collector. Such property has been examined by dynamic viscoelastic measurements at small shear deformation to avoid disturbing its microstructure. The evolution of storage (G') and loss modulus (G”) as a function of time is shown for $\mathrm{pH}$ 2.5, 4 and 6 in Figure S3. All slurries exhibited a gel-like behavior (G'>G”) over tens of minutes. This particular behavior signifies that the original dispersion state is frozen and retained once the electrode slurry has been pasted onto the current collector, whatever the $\mathrm{pH}$. The G' and G', moduli increase with the neutralization degree, indicating that the strength of the gel, and thus the stability of the slurry, increases with higher neutralization degree. This is because the silicon and graphite particles tend to agglomerate at lower $\mathrm{pH}^{53,54}$

The porosity of the as-obtained dried electrodes increases slightly with increasing $\mathrm{pH}$ (Table 1). This characteristic of electrode is likely more related to the particles geometry and their arrangement in space than to the water content in the slurry. We assume that the higher porosity is due to the more agglomerated particles in the electrodes prepared at $\mathrm{pH} 2.5 .^{55}$

To summarize, the viscosity of the electrode slurries was successfully adjusted to an optimal value with a gel-like behavior to achieve a stable dispersion and further reproducible coating quality. As the copper current collector was suspected to react with the electrode slurry during the drying process, the following section deals with the study of the current collector/electrode interface with complementary characterization techniques. 


\section{Current collector / electrode interface study by SEM, and EDX and XPS}

spectroscopies. - Metallic copper collector is naturally passivated, covered by surface species such as cupric $(\mathrm{CuO})$ and/or cuprous $\left(\mathrm{Cu}_{2} \mathrm{O}\right)$ oxides. ${ }^{56}$ The study conducted by Gil et al. ${ }^{57}$ about the atmospheric corrosion of copper in the presence of organic acids suggests that copper current collector corrosion may take place within the typical time frame of the electrode drying process at the lab scale (several hours), due to the presence of the $\mathrm{PAAH}_{1-\mathrm{x}} \mathrm{Li}_{\mathrm{x}}$ acidic groups in the electrode slurry. This reaction leads to the formation of cuprous oxide, copper carboxylates and other derivative components at the surface of copper current collector. ${ }^{57}$ Furthermore, Hernandez et al. proposed a maturation procedure for performance improvement of Si electrodes which consists in storing the electrodes prepared in a buffer solution at $\mathrm{pH} 3$ in a controlled humidity atmosphere at $25^{\circ} \mathrm{C}$ for a few days. ${ }^{7}$ It was understood that atmospheric-induced copper collector corrosion, on the one hand releases $\mathrm{Cu}^{2+}$ species, which are able to migrate into the humidified electrode and to physically crosslink binder chains, substantially modifying its resiliency to the silicon volume variation; ${ }^{8,58}$ and on the other hand favors the formation of copper carboxylate anchoring bonds at the interface between the electrode and the current collector for a stronger adhesion. ${ }^{7}$ From the Pourbaix diagram of copper (Figure S4), we note that the corrosion of the current collector with the release of $\mathrm{Cu}^{2+}$ species is expected for $\mathrm{pH} \leq 4$ under atmospheric pressure. In the following paragraphs, the occurrence of current collector corrosion during the electrode drying with slurries prepared at $\mathrm{pH}$ 2.5, 4 and 6 is quantified through SEM-EDX (on the electrode interface) and XPS characterizations (on the current collector interface), while morphological differences within the corresponding electrodes are probed from SEM observations.

The current collector surface was observed by SEM after separation of the electrode from the current collector (see experimental section). Note that electrode residues sparsely remained at 
the current collector surface depending on local adhesion strength. No washing process was applied here to remove them in order to avoid any further modification. Figure 2a-c displays the SEM images, taken over a clear view of the copper current collector, i.e. with no electrode residue, corresponding to electrode coatings prepared at $\mathrm{pH} 2.5$, 4 and 6, respectively. A pristine copper foil surface (only cleaned by ethanol) is shown in Figure 2d for comparison purpose. The latter appears flawless apart from scratched lines, typically occurring during the foil fabrication process. An electrode slurry at pH 6 barely reacts with the copper surface, as shown in Figure 2c where scratched lines are still visible. On the contrary, with a slurry prepared at $\mathrm{pH} 4$ corrosive stings are clearly visible (Figure $\mathbf{2 b}$ ) in agreement with the Pourbaix diagram. The boundaries found at $\mathrm{pH} 4$ (Figure S4) indicate that an equilibrium involving metallic copper, cuprite $\left(\mathrm{Cu}_{2} \mathrm{O}\right)$ oxide and $\mathrm{Cu}^{2+}$ species is possible. These phases can then form or exist simultaneously at the electrode/collector interface. The micro-holes on the copper surface could be explained by the organic acid attacks on the current collector, as seen also in the study of Hernandez et al.. ${ }^{7}$ Furthermore, at $\mathrm{pH} 2.5$, the copper surface appears deeply corroded (Figure 2a) and reveals an altered morphology with the presence of a glue-like layer, which composition remains unknown at this stage.

Contrarily, the corresponding SEM images on the electrode side facing the collector do not show any significant differences between the explored pHs, as seen in Figure S5a-c. EDX spectroscopy measurements were performed for element quantification. Table 1 lists the $\mathrm{Cu}$ quantification for each $\mathrm{pH}$. The amount of $\mathrm{Cu}$ close to the electrode surface facing the current collector at $\mathrm{pH} 2.5$ is drastically higher than those at $\mathrm{pH} 4$ and 6 (3.53, 0.27 and 0.15 at\%, respectively). This result confirms that a much more intense corrosion was experienced at $\mathrm{pH} 2.5$, in agreement with the SEM observations of the collectors, and indicates that copper has migrated in the electrode in significant amount at $\mathrm{pH} 2.5$. 
The sample preparation approach used for SEM imaging was also applied to XPS analysis. The acquisitions of $\mathrm{C}$ 1s, O 1s, Cu 2pand Si 2p core peaks were carried out for both electrode and current collector sides of the electrode/current collector interface (selected analyses are shown in Figure 3 and full spectra are shown in Figure S6 \& S7).

The presented spectra for the current collector side in Figure 3a are normalized with respect to the height of the metallic copper (green) peak. The $\mathrm{Cu} 2 \mathrm{p}$ core peaks exhibit a split in two spin-orbit components, $\mathrm{Cu} 2 \mathrm{p}_{3 / 2}$ and $\mathrm{Cu} 2 \mathrm{p}_{1 / 2}$, with a binding energy (BE) difference $\Delta_{\mathrm{BE}}$ of $19.75 \mathrm{eV}$ and an area intensity ratio of 0.5 . Prior to interpreting the results, it is worth mentioning that an accurate quantification of $\mathrm{Cu}^{2+}$ species is challenging. The short acquisition time, fixed at $180 \mathrm{~s}$, allows considering constant the amount of $\mathrm{Cu}^{2+}$ reduced into metallic copper under the $\mathrm{X}$ ray beam for all the samples. Taking into account the $\mathrm{Cu} 2 \mathrm{p}_{3 / 2}$ component only, the peak for metallic copper (green) appears at $932.3 \mathrm{eV}$ along with another peak shifted at $934.3 \mathrm{eV}$, assigned to oxidized $\mathrm{Cu}^{2+}$ (blue). In addition, two broad peaks at $939.4 \mathrm{eV}$ and $944 \mathrm{eV}$ were identified as $\mathrm{Cu}^{2+}$ satellite peaks. Graphically, the integrated intensity of the $\mathrm{Cu}^{2+}$ contribution is clearly more significant at the electrode interface for a slurry prepared at $\mathrm{pH} 2.5$ compared to those neutralized at pH 4 and pH 6. It is confirmed by XPS quantification. At pH 2.5, the $\mathrm{Cu}^{2+} / \mathrm{Cu}$ integrated intensity ratio is 5.5 but this value falls down to 2.2 and 2.1 for $\mathrm{pH} 4$ and $\mathrm{pH} 6$, respectively. These quantitative results reported in Table $\mathbf{1}$ confirm once again that the collector has been submitted to an intense corrosion during the electrode processing at $\mathrm{pH} 2.5$, but this corrosion reaction was largely restrained in the case of $\mathrm{pH} 4$ and 6.

Figure $3 \mathbf{b}$ shows the $\mathrm{Cu} 2 \mathrm{p}$ core peaks of the electrode surface initially facing the current collector. In this plot the $\mathrm{Cu} 2 \mathrm{p}$ core peak was normalized with the height of the main $\mathrm{Cu}^{2+}$ (blue) peak (see experimental part). It reveals that $\mathrm{Cu}^{2+}$ species have migrated in the electrode in the 
vicinity of the current collector and are most likely coordinated with carboxylate ligands as reminded above. ${ }^{7}$

The Si 2p XPS spectra of the same electrode surface (in contact with the current collector) are displayed in Figure 3c. All the spectra were normalized with respect to the height of the elementary silicon (purple) peak, localized at $99.5 \mathrm{eV}$. The Si 2p core peaks have also two spinorbit components, Si $2 \mathrm{p}_{1 / 2}$ and Si $2 \mathrm{p}_{3 / 2}$, but closely spaced in $\mathrm{BE}\left(\Delta_{\mathrm{BE}}=0.63 \mathrm{eV}\right)$ making them undistinguishable. The two other Si 2p peaks at $102.3 \mathrm{eV}$ (pink, labelled Si2) and $103.6 \mathrm{eV}$ (green, labelled $\mathrm{Si} 3)$ are assigned to $\mathrm{Si}-\mathrm{OC}(\mathrm{O})-\mathrm{R}^{58}$ ester bonds or $\mathrm{SiO}_{\mathrm{x}}(\mathrm{x}<2)$ on the silicon surface and other more oxidized surface components like $\mathrm{SiO}_{2}$ or $\mathrm{SiOH}$, respectively. ${ }^{59}$ In addition, a shift of $0.2 \mathrm{eV}$ to higher $\mathrm{BE}$ of $\mathrm{Si} 2$ and $\mathrm{Si} 3$ peaks is observed for $\mathrm{pH} 6$ compared to $\mathrm{pH}$ 2.5. This shift could be explained by the favored silicon oxidation to $\mathrm{SiO}_{2}$ for neutral $\mathrm{pH}$, while such a reaction is hindered in acidic slurry. ${ }^{36,37}$ Furthermore, the $\mathrm{Si} 2 / \mathrm{Si} 3$ integrated intensity ratio for each electrode $\mathrm{pH}$ was calculated and given on Figure 3c. Indeed, this $\mathrm{Si} 2 / \mathrm{Si} 3$ ratio can give information on the relative amount of silicon atoms at the surface that have been experiencing a grafting reaction with polyacrylic acid during electrode processing ( $\mathrm{SiOH}+\mathrm{R}-\mathrm{C}(\mathrm{O}) \mathrm{OH} \rightarrow \mathrm{R}-$ $\left.\mathrm{C}(\mathrm{O}) \mathrm{OSi}+\mathrm{H}_{2} \mathrm{O}\right)$. A higher ratio is found for acidic pHs, in agreement with previous works. ${ }^{58}$ However, the obtained non-linear trend suggests a complex behavior that cannot be simply explained by the above $\mathrm{pH}$-dependent grafting mechanism only.

The C 1s core peaks on the same electrode surface are presented in Figure 3d. Six different carbon environments were identified for all the electrodes, independently of the $\mathrm{pH}$ of preparation. The asymmetric C1 peak (green) is assigned to graphite double bonding centered at $284.4 \mathrm{eV}$. All the spectra were normalized with respect to this peak height. This component goes together with the C6 peak (orange) localized at around $290.8 \mathrm{eV}$ and assigned to the $\pi$ to $\pi^{*}$ transition. Similarly, 
C2, C3 and C4 peaks are associated to adventitious carbon contamination and correspond to the contributions of $\mathrm{C}-\mathrm{C} / \mathrm{C}-\mathrm{H}, \mathrm{C}-\mathrm{OH}$, and $\mathrm{C}=\mathrm{O}$ bonds, respectively ${ }^{60}$ The $\mathrm{C} 5$ peak corresponds to carboxylate groups $(\mathrm{O}-\mathrm{C}=\mathrm{O})$ of the binder bonded to all types of cations, including protons, silicon, copper and lithium cations. However, owing to quite similar electronegativity values for $\mathrm{H}$, $\mathrm{Si}$ and $\mathrm{Cu}$, it is not possible to distinguish between these different possible contributions to the C5 peak. This is further illustrated in Figure S8, in which C5 peak contributions from PAAH and $\mathrm{PAAH}_{0.9} \mathrm{Cu}_{0.05}$ rise at the same BE. The minor shift of $\mathrm{C} 5$ peak to lower $\mathrm{BE}$ that can be noticed at pH 6 (Figure 3d) is attributed to the addition of $\mathrm{LiOH}$ in the formulation for the $\mathrm{pH}$ adjustment. ${ }^{58}$ It can also be noted that the $\mathrm{C} 5$ peak of the binder is a little more intense at $\mathrm{pH}$ 2.5. This observation could testify to an accumulation of reaction products between the binder and the copper current collector (copper polyacrylates) at this interface. The full spectra (C 1s, O 1s, Cu 2pand Si 2p core peaks) from both sides of the electrode/current collector interface are shown in Figure S6 \& S7. Except for $\mathrm{Cu} 2 \mathrm{p}$, which is discussed above, other spectra for each element are very similar.

In summary, the corrosion of the $\mathrm{Cu}$ current collector surface occurring after coating the electrode slurry onto the collector is highly dependent of the acidity of the electrode slurry. It is strong at $\mathrm{pH} 2.5$, very mild at $\mathrm{pH} 4$ and not detectable at $\mathrm{pH}$ 6. SEM-EDX and XPS quantitative measurements confirm these observations. The precise quantification of carboxylate groups bonded to protons, $\mathrm{Cu}^{2+}$ or silicon surface was not possible. A higher extent of covalent grafting of the binder to the silicon surface when the electrode was prepared in acidic conditions $(\mathrm{pH} 2.5$ and 4) is however suggested by the larger $\mathrm{Si} 2 / \mathrm{Si} 3$ integrated intensity ratio. Moreover, the slightly higher intensity of the corresponding $\mathrm{C}$ 1s peak for the electrode prepared at $\mathrm{pH} 2.5$ is consistent with the expected larger amount of byproducts due to an exacerbated corrosion. $\mathrm{As}^{\mathrm{Cu}^{2+}}$ species may diffuse throughout the electrode thickness, the electrode top surface was examined as well. 
Electrode top surface study by SEM and XPS spectroscopy. - Despite an adjustedviscosity slurry, the migration of binder to the top of the electrode during its drying is favored under humid conditions. ${ }^{61,62}$ This migration, if it takes place, results in a depletion of binder within the electrode and at the interface with the current collector, which are detrimental for electrode integrity and adhesion, ${ }^{61,62}$ as delamination issues are reported as the principal cause for Si-based electrode failure. ${ }^{7,8,63}$ The SEM images taken at the top surface of electrode for pH 2.5, 4 and 6 do not show any significant binder enrichment, which would appear as an amorphous surface layer, whatever the $\mathrm{pH}$ of the preparation (Figure S5d-f), suggesting if a migration phenomenon has occurred, it is very slight. ${ }^{64}$

In complement, the measurements of XPS C 1s, O 1s, Cu 2pand Si 2p core peaks were also carried out on the electrode surface near separator side, and are shown in Figure S9. Noteworthy, some traces of copper are revealed on the $\mathrm{Cu} 2 \mathrm{p}$ core peaks XPS spectra, although only a low resolution could be achieved owing to the very low copper amount present. The copper detected corresponds most likely to $\mathrm{Cu}^{2+}$ ions stemming from the corrosion reaction at the slurry/current collector interface that then migrated throughout the electrode slurry up to the top of the electrode coating. Nevertheless, the obtained $\mathrm{Cu} 2 \mathrm{p}$ spectra strongly suggest a larger amount of $\mathrm{Cu}^{2+}$ in the case of the electrode prepared at $\mathrm{pH}$ 2.5. Indeed, $\mathrm{Cu} 3$ and $\mathrm{Cu} 4$ satellite peaks are clearly more resolved and the signal-to-noise ratio has a better quality for the $\mathrm{pH} 2.5$ electrode for the same counting time. This results supports the more effective $\mathrm{Cu}^{2+}$ migration across the electrode thickness for electrode prepared at low $\mathrm{pH}$. Moreover, for all the spectra, a minimal metallic copper amount appears as a consequence of the aforementioned X-ray beam damage. For all the other elements, the spectra are very close to those obtained on the side of the current collector (fully shown in Figure S6) and on the electrode side facing the current collector (fully shown in Figure 
S7), suggesting that the electrodes have very similar compositions on their surfaces and close to the current collector, and therefore probably in their thicknesses, except for $\mathrm{Cu}^{2+}$ that is present in larger quantity at $\mathrm{pH}$ 2.5. In the following the mechanical properties of the electrodes are further characterized and interpreted in terms of the nature of the functional groups carried by the binder and their coordination bonds with the Si surface and with the current collector surface.

Scratch test. - Scratch tests were performed to establish a relation between the cohesion and adhesion strengths of as-made Si/Gr electrodes and the $\mathrm{pH}$ of the corresponding slurry. Indeed, both properties are crucial for the cycle life of Si-based electrodes. Table 1 shows the load necessary to scrape the electrode coating from the copper current collector. The appreciation of scratch is supported by SEM-BSE (Back-Scattered Electrons) images, as given in Figure S10. The critical load reaches $400-450 \mathrm{~g}$ for an electrode prepared at $\mathrm{pH} 2.5$, slightly decreases at 350$400 \mathrm{~g}$ for a pH 4 electrode, and severely drops at $150-200 \mathrm{~g}$ for a pH 6 electrode. This trend is in agreement with the peel test results carried out by Hu et al. on Graphite-rich negative electrodes, although they found a much more regular decrease of the peel strength with increasing the $\mathrm{pH} .{ }^{34}$

The critical load depends on both the intrinsic mechanical strength of the binder and on its adhesion properties toward the particles and the current collector surfaces. ${ }^{65}$ Several factors can play on the mechanical strength of the binder. Firstly, its intrinsic mechanical strength could be modified by the presence of $\mathrm{Cu}^{2+}$ species throughout the thickness of the electrode. XPS and EDX results indeed indicated that the corrosion of the copper current collector surface increases dramatically by lowering the electrode slurry $\mathrm{pH}$. As a consequence of the migration of $\mathrm{Cu}^{2+}$ species across the wet electrode film, physical cross-linking of PAA chains can be expected through the formation of copper carboxylate coordination bonds, which could enhance the mechanical strength of the binder. ${ }^{58}$ Secondly, it was shown by Porcher et al. ${ }^{29}$ that silicon particles 
are homogeneously coated by a thin layer of binder when fully lithiated PAALi was used, while for poly(acrylic acid) PAAH, a heterogeneous distribution of binder islands deposited on the silicon particles surface is observed. Nearly the same conclusion was inferred by Komaba et al. but with respect to graphite material. ${ }^{40}$ Furthermore, it is also possible that the conformation of the polymer chains at the surface of the particles differs as a function of the $\mathrm{pH}$ of the slurry. It is assumed that an orientation more parallel to the surface can be expected for less acidic pHs due to an elongated chains conformation in solution, ${ }^{52}$ which refers to the electrostatic repulsions between the charged carboxylate groups. On the contrary, a more folded conformation can be expected for more acidic pHs since the chains display a coiled conformation via intra-chain hydrogen bonding in solution. ${ }^{52}$ These different patterns of arrangement of the binder on the surface of the silicon and graphite particles could also influence the mechanical strength of the binder bridges at interparticle junctions and thus the electrode cohesion. These different patterns are tentatively schematized in Figure 4a, where only spherical particles are considered for the sake of clarity.

Moreover, under acidic processing conditions, the grafting of the PAA chains to the silicon surface through ester bonds (as suggested by XPS here) and the establishment of electrostatic interfacial interactions mediated by the $\mathrm{Cu}^{2+}$ species are also expected to improve the overall electrode cohesion. The different types of bonds between the binder and the surface of the silicon particles are tentatively schematized in Figure $\mathbf{4 b}$. Furthermore, the anchoring of the binder at the current collector surface, again through copper carboxylate coordination bonds should enhance the adhesion at this interface.

In short, the cohesion of the electrode and its adhesion onto the current collector determined from the scratch tests depend strongly on the preparation $\mathrm{pH}$. They have been interpreted in terms of homogeneity of the binder coverage at the surface of the active materials particles, in relation 
to the type of bonds between the binder and the surface, schematized in Figure 4. Several reasons may be at the origin of the higher scratch resistance after processing in acidic conditions, i.e. stronger adhesion at the current collector surface and at the silicon particles, and stronger cohesion of the binder phase. As a consequence of the contrasted mechanical properties and chemical compositions, different cycling behavior might be obtained for electrodes prepared at $\mathrm{pH} 2.5,4$ and 6.

Electrochemical behavior at the first cycle. - The electrochemical behavior for the $1^{\text {st }}$ cycle is examined as a function of the electrode preparation conditions in Figures 5a-d. From the incremental capacity analysis (Figure 5a), contributions of the two active materials, silicon and graphite, are well defined and in accordance with individual silicon and graphite electrochemical behaviors. ${ }^{66}$ During the first discharge, incremental capacity peaks at $0.26 \mathrm{~V}$ and $0.07 \mathrm{~V}$ are assigned to silicon electroactivity while graphite peaks are located at $0.18 \mathrm{~V}, 0.09 \mathrm{~V}$ and $0.06 \mathrm{~V}$. The sharp peak at $0.26 \mathrm{~V}$ is assumed to be related to the lithiation of partially crystallized pristine silicon powder. ${ }^{67}$ According to Key et al., it corresponds to the Si-Si bond breakage within the crystalline structure upon lithium incorporation at the silicon surface. ${ }^{68}$ During the subsequent charging process, lithium is firstly extracted from graphite at $0.13 \mathrm{~V}, 0.17 \mathrm{~V}$ and $0.24 \mathrm{~V}$. Lithium dealloying from silicon appears as a broad peak around $0.3 \mathrm{~V}$ followed by a sharp peak at $0.45 \mathrm{~V}$, the latter is resulting from the transformation of the crystalline $\mathrm{Li}_{15} \mathrm{Si}_{4}$ compound into an amorphous $\mathrm{Li}_{2} \mathrm{Si}$ phase through a two-phase reaction. ${ }^{67}$ The lithiation/delithiation mechanism of the silicon used here is thus typical of a mixed amorphous/crystalline silicon. ${ }^{67} \mathrm{~A}$ statistical analysis of the crystallinity of the silicon studied here was carried out by micro-Raman spectroscopy (Figure S11). The measurements taken randomly in different areas of the sample 
indicated a strong inhomogeneity in terms of the distribution of amorphous or crystalline silicon, in agreement with the electrochemical behavior.

Figure 5b displays the discharge/charge potential curves as a function of the specific capacity for the first cycle of $\mathrm{Si} / \mathrm{Gr}$ electrode for each $\mathrm{pH}$ of electrode preparation. The initial reversible capacity measured upon delithiation is close to $1800 \mathrm{mAh} \mathrm{g}^{-1}$ at $\mathrm{pH} 2.5$ or $\mathrm{pH}$, and reaches $1900 \mathrm{mAh} \mathrm{g}^{-1}$ at $\mathrm{pH} 4$ (see Table 1), close to the theoretical capacity (1975 mAh g${ }^{-1}$ ). The initial coulombic efficiency (ICE) remains in the range 89-91 \%, larger than usual range of 60-85 $\%$ reported for silicon/graphite anode ${ }^{69}$ and nevertheless increases slightly with increasing preparation $\mathrm{pH}$ (Table 1). It is worth to highlight that the Si/Gr electrode prepared at $\mathrm{pH} 4$ performs with a high areal reversible capacity of more than $6 \mathrm{mAh} \mathrm{cm}^{-2}$ and with an ICE very close to that of commercial graphite anodes in a 90-94 \% range.$^{69}$ Note that the electrode irreversibility during the first cycle is particularly studied for commercial battery applications and the highest possible ICE is obviously targeted in order to preserve the lithium inventory and to reach a satisfactory LIB lifespan.

The first cycle irreversible capacity loss finds its origin in several causes: (i) the formation of the solid electrolyte interphase (SEI) layer, constituted of electrolyte decomposition products; ${ }^{30,70,71}$ (ii) electrical disconnection of active particles; and (iii) the PAA electrolithiation. ${ }^{29,31}$ According to interrupted FIB/SEM experiments presented elsewhere, ${ }^{72}$ the electrical disconnection of active particles is less likely at the first cycle for these electrodes. Concerning the electro-lithiation of PAA, Nguyen et al. reported that the reduction of the PAA carboxylic acid groups occurs at $1.6 \mathrm{~V}$, thus prior to the electrolyte decomposition. ${ }^{41}$ Inspired by the work of Porcher et al., ${ }^{29}$ an hypothesis was made by supposing that the non-neutralized PAA initially in the electrode slurry preparation will be fully lithiated upon the first discharge, thus the additional 
irreversible capacity due to PAA electro-lithiation (PAAH $+\mathrm{Li}^{+}+\mathrm{e}^{-} \rightarrow$ PAALi $+1 / 2 \mathrm{H}_{2}$ ) has been calculated (in SI). Hence, the intrinsic ICE, i.e. the contribution to the ICE of other factors than PAA electro-lithiation (mainly SEI formation), can be obtained by simple subtraction. The results are shown in Figure 5c. The intrinsic ICE still shows an increasing trend as a function of electrode $\mathrm{pH}$, even when considering the error bars.

To better understand the influence of the PAA neutralization degree on the intrinsic ICE at first cycle, we paid attention to the irreversible capacity peak around 1 - $0.6 \mathrm{~V}$ in the first discharge (Figure 5a inset), attributed to the FEC decomposition. ${ }^{26,30,73,74}$ The variation of integrated intensity of this peak as a function of the $\mathrm{pH}$ of the binder solution is given in Table 2 and is plotted in Figure 5d. The capacity values obtained are extremely low (less than $0.5 \%$ of the total capacity loss, see Table 2). But the electrode at pH 6 exhibits the lowest irreversible capacity associated to FEC decomposition, followed by the electrode at $\mathrm{pH} 4$ then finally the electrode at $\mathrm{pH}$ 2.5, in agreement with the intrinsic ICE trend. A second reduction peak can be distinguished between 0.40 and $0.30 \mathrm{~V}$ (Figure 5a inset), also assigned to electrolyte degradation. The corresponding irreversible reduction capacity remains very low as well (about $5 \%$ of the total capacity loss, Table 2 and Figure 5d). However, it strongly decreases at increasing preparation $\mathrm{pH}$. Both solvent decomposition capacities thus decrease with increasing neutralization degree of PAA binder, which is consistent with the artificial SEI properties of the binder, showing more homogeneous coverage of the Si surface at higher $\mathrm{pH}$ as illustrated in Figure 4a. The sum of PAA electro-lithiation, electrolyte reductions capacities only represent a small fraction of the total capacity loss. It can be assumed that the further electro-reduction of the electrolyte will occur at lower potential upon the silicon lithiation that will induce the volume expansion of the particles 
and likely exposition of new electroactive surfaces and/or SEI thinning, which will account for the remaining capacity loss.

Moreover, it is worth to point out that the onset potential of FEC decomposition during the first discharge increases with the $\mathrm{PAAH}_{1-\mathrm{x}} \mathrm{Li}_{\mathrm{x}}$ neutralization degree (Figure 5a inset). In the work of Shen et al., it has been shown that thickening a polymeric artificial SEI grafted to the silicon surface shifts the electrolyte reduction peak to lower potential. ${ }^{75}$ They attributed this behavior to a hindered kinetic ability of lithium ions to penetrate through thicker binder layer hampering the electrolyte reduction on the silicon surface. ${ }^{75}$ Karkar et al. also found a shift of the reduction peak to lower potential together with a decreasing integrated intensity of this peak with an increase of the binder content (PAA or CMC) in the electrode composition. ${ }^{26}$ In the present case it is difficult to postulate the influence of the binder layer thickness as the binder content is the same in all electrodes. Furthermore, the binder presumably adopts different deposition patterns, i.e. from homogeneous at $\mathrm{pH} 6$ to heterogeneous (roughened) at $\mathrm{pH}$ 2.5. Difference in the permeability of the binder layer to the electrolyte could also affect the onset potential of FEC decomposition. ${ }^{76}$ Indeed, FEC has a large permittivity $(\mathrm{Er}=110)^{77}$ and a highly charged binder layer such as for pH 6 could facilitate the passage of the electrolyte through this layer because of the dissociation of the lithium carboxylate groups. As a matter of fact, the ionization of the $\mathrm{COO}^{-}-\mathrm{Li}^{+}$bonds must facilitate the separation of the polymer chains via the electrostatic repulsion between the neighboring carboxylates and the swelling of the polymer layer by the electrolyte. According to this hypothesis, the binder layer in the electrode prepared at $\mathrm{pH} 2.5$ would be less permeable to the electrolyte initially because of the numerous intra- and inter-chains hydrogen bonds. Even if the carboxylic acid functions are reduced to lithium carboxylates during the first cycle, this reaction can only occur gradually. It probably begins at the extreme surface of the binder layer in contact 
with the electrolyte. This would explain that the reduction in FEC occurs later (at lower potential) with decreasing neutralization degree $\mathrm{x}$ of the $\mathrm{PAAH}_{1-\mathrm{x}} \mathrm{Li}_{\mathrm{x}}$ (from $\mathrm{pH} 6$ to $\mathrm{pH} 2.5$ ).

To summarize this part, the highly loaded electrodes prepared here deliver an initial reversible capacity in the range 1800-1900 $\mathrm{mAh} \mathrm{g}^{-1}\left(>6 \mathrm{mAh} \mathrm{cm}^{-2}\right)$ with a high ICE, close to 90\%, much larger than the usual 60-85\% range reported for silicon/graphite electrodes. The first cycle irreversible capacity loss was analyzed in terms of PAA electro-lithiation, and contribution of electrolyte reductive decomposition. It was shown that these contributions only account for a very small part of the total loss. However, they foreshadow the extent of electrolyte reduction that occurs at lower potential as the volume of silicon increases upon lithium insertion. The lower intensities of the peaks characterizing the electrolyte solvent reduction and the higher ICE obtained for the electrode prepared in neutral condition confirms the better artificial SEI properties of PAA at increasing neutralization degree, which is attributed to more homogeneous covering of the $\mathrm{Si}$ and Gr particle surface.

Morphological evolution upon cycling. - As it can be seen in Table 1, at the end of the first cycle, the electrode mass gain is much higher for the electrode prepared at $\mathrm{pH} 2.5$ compared to the two other electrodes (15.7, 5.5 and $4.1 \%$ at $\mathrm{pH} 2.5,4$ and 6 , respectively). This trend is in agreement with the formation of a drastically larger amount of SEI species coming from a stronger electrolyte degradation at $\mathrm{pH}$ 2.5. However, the ICE decreases linearly with the $\mathrm{pH}$, suggesting that part of the degradation products at $\mathrm{pH} 2.5$ may also relate to chemical decomposition rather than electrochemical reduction. As Hays et al. ${ }^{31}$ reported, PAAH-based Si/Gr electrode is 3.5 times more hydroscopic than the one of PAALi-based, which provides a larger amount of water traces for developing the chemical degradation of $\mathrm{LiPF}_{6}$ and FEC. 
Figure 6a-c displays SEM images of electrode surface which were prepared at $\mathrm{pH}$ 2.5, 4 and 6 at the end of $1^{\text {st }}$ cycle. Others images taken at the scale of particle size are given in Figure S13. The pristine electrode prepared at $\mathrm{pH} 4$ is shown in Figure S12 as a reference. All pristine electrodes present a similar aspect at this magnification whatever the $\mathrm{pH}$ of preparation. These images were acquired with great care in the center of electrode to avoid regions near the possibly damaged edge of the electrode. They are given under a macroscopic view in order to get a visual glimpse at their mechanical integrity. At the end of $1^{\text {st }}$ charge, visual aspects of the three electrodes differ strongly indicating different mechanical behaviors according to the $\mathrm{pH}$ of preparation. Both pH 2.5 and 6 electrodes show a cracking after the delithiation. This is in contrast with the pH 4 electrode, for which very few cracks are observed after 1 cycle, as also observed with complementary FIB/SEM interrupted experiments detailed elsewhere. ${ }^{78}$ It should be noted that the resistance to cracking of the electrodes during the first electrochemical cycle does not follow the trend shown in the scratch test. The two mechanical tests are, however, not equivalent as they are not experienced under the same condition, i.e. in presence/absence of electrolyte and heterogeneous/homogeneous deformation.

Cracks formed mainly during the delithiation of the Si active mass necessarily results from a rupture of the binder bridges between the particles, by scission or disentanglement of the polymer chains, and/or from the detachment of the binder from the surface of the active mass. The significant cracking of the electrode prepared at pH 2.5 could result from too much rigidity, linked to a high density of chain entanglements and to intensive copper carboxylate crosslinking of the binder. This lack of flexibility or deformability could not allow the electrode to reversibly sustain the enormous expansion/contraction during cycling if the deformation imposed on the binder bridges exceeds their elastic deformation limit. The better strength of the electrode prepared at $\mathrm{pH}$ 
4 may result from a lower rigidity and a greater limit of elastic deformation of the polymer bridges, due to lower density of chain entanglements and less physical crosslinking. For the electrode prepared at $\mathrm{pH}$ 6, the significant cracking is consistent with its lower macroscopic cohesion and adhesion strengths measured at the scratch test. It could be attributed to the lower adhesion of the binder to the surface of the Si active mass. The already elongated conformation of the polymer chains may also limit the possibility for this binder to assume significant stretching during the first lithiation. It should be noted that due to the (de)alloying reaction, the surface composition of the silicon particles changes during a cycle. Maintaining the cohesion of the electrode relies on the ability of the binder to maintain adhesion to this living surface. This aspect is very little described and remains misunderstood to this day. Furthermore, from Figure S13 a-c, at the end of first cycle, a deposit of SEI components on both silicon and graphite surfaces is observed for all pHs, but it seems visually thicker for the $\mathrm{pH} 6$ electrode.

In summary, SEM images at the end of the first cycle reveal cracking at the electrode surface for $\mathrm{pH} 2.5$ and 6, but not for $\mathrm{pH}$ 4. It was interpreted in terms of binder chain entanglements, physical crosslinking, and adhesion to the active material surface, that differ when $\mathrm{pH}$ varies.

NMR spectroscopy. - Although the chemical composition of SEI depends on the electrolyte components, it consists typically in a mix of inorganic products such as $\mathrm{LiF}$ and lithiated or non-lithiated organic species stemming from the degradation of the carbonates used as the electrolyte solvents. Therefore, to screen lithium and fluorine local chemical environments, their distribution at the surface of active materials and the chemical composition of the SEI, ${ }^{7} \mathrm{Li}$ and ${ }^{19} \mathrm{~F}$ MAS NMR analysis were performed before cycling (after exposure to the electrolyte) and at the end of the first charge for each $\mathrm{pH}$-adjusted electrode. Previous works in the group reported that 
all the lithium is extracted from silicon at the end of charge. ${ }^{45,46,79}$ Experiments have been therefore performed at the end of the delithiation process of the electrode in order to detect only Li nuclei involved in the SEI.

${ }^{7} \mathrm{Li}$ and ${ }^{19} \mathrm{~F}$ NMR spectra are presented in Figure S14. In the case of ${ }^{7} \mathrm{Li}$ NMR, the asymmetric peak suggests that at least two different local environments could be identified for the lithium nuclei in the electrode/electrolyte interphase. Nevertheless, the chemical shift range for diamagnetic lithium is quite narrow and all the resonances corresponding to lithiated species belonging to the SEI rise typically between -2 and $2 \mathrm{ppm}$ and then it becomes challenging to discriminate their respective contributions. ${ }^{45,80,81}$ The broader component of this asymmetric resonance seems to be characterized by a strong negative chemical shift, indicating an additional contribution to a purely chemical shift. Indeed, negative shifts of diamagnetic Li have been reported in the case of Li cation surrounded by the $\pi$ electron clouds generated by graphite. ${ }^{82}$ In order to verify the validity of such an hypothesis here, LiF powder has been intimately mixed by ball-milling with pure silicon and blended Si/Gr, in a $5 \mathrm{wt} \%$ ratio. The corresponding ${ }^{7} \mathrm{Li}$ MAS NMR spectra are shown in Figure 7a. While a sharp resonance at $-1 \mathrm{ppm}$ is observed for LiF mixed with pure silicon, a broad and strongly shifted resonance appearing at approx. $-15 \mathrm{ppm}$ is seen in the case of LiF mixed with Si/Gr sample. Therefore, as shown in Figure S14a concerning the Si/Gr electrodes studied in this work, we assign the sharp component at approx. $-2 \mathrm{ppm}$ to the diamagnetic lithiated species deposited on the silicon surface ${ }^{45,83}$ whereas the broad component at approx. $-15 \mathrm{ppm}$ is linked to lithiated species deposited on the graphite surface.

For the ${ }^{19} \mathrm{~F}$ NMR, the same peak identification protocol used for ${ }^{7} \mathrm{Li}$ NMR was applied. In Figure $7 \mathbf{b}$, the ${ }^{19} \mathrm{~F}$ NMR spectra displayed only the typical resonance of LiF at $-205 \mathrm{ppm}$ in the case of pure silicon. But this resonance is quite broadened and shifted to $-215 \mathrm{ppm}$ in the case of 
the Si/Gr sample. No additional resonance could be observed apart from the spinning sidebands, confirming the chemical integrity of LiF and the absence of reaction that would be induced by the ball-milling process. Moving now to the ${ }^{19}$ F NMR spectra of electrodes (Figure S14b), four resonance peaks were identified and considered for spectral fits. The major resonance visible at approx. -208 ppm is assigned to LiF. As discussed in the above paragraph, the presence of graphite seems also to influence the NMR signal acquired for LiF, broadening it and shifting it towards more negative NMR shifts. Unlike ${ }^{7} \mathrm{Li}$ NMR spectra, the strong overlap of the two relatively broad resonances attributed to $\mathrm{LiF}$ at the surface of silicon and $\mathrm{LiF}$ at the surface of graphite makes it impossible to clearly differentiate their respective contributions (Figure 7b). Thus, in the following, the fit of ${ }^{19} \mathrm{~F}$ spectra will consider only one broad peak corresponding to the combined aforementioned contributions. As a result, in Figure S14b, this peak appears slightly shifted to negative at $-208 \mathrm{ppm}$ compared to the expected value at $-205 \mathrm{ppm} \cdot{ }^{79,81}$ A possible $\mathrm{SiO}_{\mathrm{x}} \mathrm{F}_{\mathrm{y}}$ contribution was detected at approx. $-150 \mathrm{ppm}$, stemming from a reaction between the electrolyte and silicon surface oxides. ${ }^{84-86}$ The resonance identified at approx. -75 ppm was attributed to residual $\mathrm{PF}_{6}{ }^{-}$groups confined in SEI porosity remaining after the washing process. In some cases, a minor resonance peak could be detected at around $-84 \mathrm{ppm}$ and assigned to $\mathrm{Li}_{\mathrm{x}} \mathrm{PF}_{\mathrm{z}}$ or $\mathrm{Li}_{\mathrm{x}} \mathrm{PO}_{\mathrm{y}} \mathrm{F}_{\mathrm{z}}$ fluorophosphates. ${ }^{79}$

The ${ }^{7} \mathrm{Li}$ and ${ }^{19} \mathrm{~F}$ quantifications of chemical species for electrodes adjusted at $\mathrm{pH} 2.5,4$ and 6, before cycling and at the end of $1^{\text {st }}$ charge, are displayed in Figure 7c. The quantification of surface diamagnetic Li takes into account the contributions corresponding to lithiated species deposited on silicon (green) and lithiated species in strong interaction with the graphite surface (orange). The results were obtained with the help of a calibration curve as described previously. ${ }^{50}$ For the Li quantification, the number of moles of lithium used to neutralize the PAA in electrode 
slurry preparation was deducted. The total amount of $\mathrm{Li}$ and $\mathrm{F}$ corresponding to the SEI quantitative measurements indicates clearly that the formation of the SEI appears in much larger amount when the electrode has been prepared at $\mathrm{pH} 2.5$ compared to other $\mathrm{pHs}$, in both cases before cycling and after one full cycle.

Comparing the total $\mathrm{Li}$ amounts obtained from ${ }^{7} \mathrm{Li} \mathrm{NMR}$ and $\mathrm{LiF}$ amounts obtained from ${ }^{19} \mathrm{~F}$ NMR, for all the electrodes before cycling or after 1 cycle, they appear quite close, as listed in Table 3. It suggests that the lithiated derivatives constituting the SEI correspond mostly to LiF. In other words, only a small amount of other lithiated species, including lithiated organic species seems to be formed. In the case of ${ }^{19} \mathrm{~F}$ NMR spectra, and in particular for $\mathrm{pH} 2.5$, due to extremely broad peaks, the background estimation and subtraction is challenging and seem to lead to a possible over-estimation of the amount of detected fluorine nuclei. For instance, the LiF quantification at $\mathrm{pH} 2.5$ from the ${ }^{19} \mathrm{~F}$ signal leads to an estimated amount of LiF larger than the total amount of lithium estimated from the corresponding ${ }^{7} \mathrm{Li}$ signal. Therefore, we tentatively presume that the SEI contains almost 100\% LiF and very little lithiated organic species. This striking result would be a consequence of the EC-free and FEC-rich specific electrolyte composition used here. Indeed, previous work found increased LiF content in the negative electrode SEI when FEC is added as an additive to standard battery electrolyte (based on EC/DEC) ${ }^{87}$ Otherwise, the comparison of ${ }^{7} \mathrm{Li}$ and ${ }^{19} \mathrm{~F}$ quantification for the electrode prepared at $\mathrm{pH} 4$ indicates that $68 \%$ and $81 \%$ of $\mathrm{Li}$ appears under the form of LiF before cycling and after 1 cycle, respectively, indicating also a major contribution of LiF in the SEI with respect to other lithiated species and a minor, as well as decreasing contribution of lithiated organic degradation products during the early stages of cycling. Overall, the same trend is observed for the electrode prepared at pH 6. 
Very interestingly, for $\mathrm{pH} 4$ and $\mathrm{pH}$ 6, one may note that approximately two-third of the lithiated species are found on graphite, which may be a consequence of an enhanced adsorption of PAA on silicon than on graphite, leading to a better pre-passivation of the silicon surface. Indeed, it is known that the surface of graphite better interacts with polymeric binders that contain hydrophobic sequences in their chain, like carboxymethyl cellulose (CMCNa). ${ }^{63,88}$ Contrarily, PAA chain is purely hydrophilic. This suggests that a PAA/CMC blend might be a better binder for negative electrodes based on $\mathrm{Si} / \mathrm{Gr}$ blends. For more acidic conditions at $\mathrm{pH} 2.5$, the relative amount of lithiated species on graphite decreases down to one half. It can be seen as a sign of the less homogenous covering of the silicon surface by the PAAH binder or of an enhanced adsorption on graphite compared to the other pHs.

Two more comments are worthwhile. First, in the non-cycled electrodes, a significantly higher amount of $\mathrm{SiO}_{\mathrm{x}} \mathrm{F}_{\mathrm{y}}$ is found at $\mathrm{pH}$ 2.5, which again underlines the less homogeneous covering of the silicon surface by the PAA binder for this $\mathrm{pH}$, as $\mathrm{SiO}_{\mathrm{x}} \mathrm{F}_{\mathrm{y}}$ is formed from the direct reaction between the electrolyte and silicon surface oxides. ${ }^{84-86}$ Second, the higher amount of $\mathrm{LiPF}_{6}$ is again found at $\mathrm{pH}$ 2.5. The analyzed electrodes were rinsed with DMC prior to NMR experiments and we assume then that the detected $\mathrm{LiPF}_{6}$ corresponds to remaining non-degraded electrolyte confined in the porosity of the SEI, which is more important at pH 2.5 .

To summarize this part, based on the observed NMR shift, it was possible to determine the distribution of lithiated species comprised in the SEI on the surface of graphite and/or silicon. This allows deducing on which surface, graphite and/or silicon, the adsorption of PAA is favored for each preparation $\mathrm{pH}$. The quantitative NMR study performed here indicates that, for all preparation $\mathrm{pH}$ investigated, the lithiated species comprised in the SEI correspond mostly to LiF. It appears also that the amount of LiF is drastically larger in the case of an electrode prepared at $\mathrm{pH} 2.5$ 
compared to the two other higher investigated pHs. This result combined with the more intense signal assigned to $\mathrm{SiO}_{\mathrm{x}} \mathrm{F}_{\mathrm{y}}$ species supports a less homogenous and thus, less efficient, covering of the surface of silicon particles by PAAH binder.

Electrochemical impedance spectroscopy - Electrochemical impedance spectroscopy (EIS) measurements were carried out on Si/Gr electrodes prepared at $\mathrm{pH}$ 2.5, 4 and 6, prior to cycling and also along the $1^{\text {st }}$ cycle, at potentials carefully selected with respect to the electroactivity of silicon and graphite. ${ }^{66}$ Prior to cycling, a first EIS measurement was taken at open circuit voltage (OCV) (3 V vs. $\mathrm{Li}^{+} / \mathrm{Li}$ ) as reference. Then, along the course of lithiation, EIS measurements were realized at $0.4 \mathrm{~V}, 0.15 \mathrm{~V}$, and $0.005 \mathrm{~V}$, followed by a final acquisition at the end of first delithiation at $1 \mathrm{~V}$ (Figure 8a). Measurements were performed after the system reached stabilization at the desired potential. In these conditions, processes related to the SEI formation at the corresponding potential are considered complete. ${ }^{89}$ Selected Nyquist plots are given in Figure 9 and the full corresponding plots EIS study are shown in the Supporting Information (Figure S15).

In all cases, the spectra are constituted of the typical semicircular components in the middle-frequency region ( $10 \mathrm{~Hz}-100 \mathrm{kHz})$ and a Warburg element in the low-frequency region (below $10 \mathrm{~Hz}$ ). At high frequency, beyond $200 \mathrm{kHz}$, the intercept of the semi-circle with the impedance real part axis is usually influenced by the experimental set-up (uncertain cable and connection resistance) and will not be explored for spectra fitting. This value gives also information on electrolyte resistance. In general, the semicircles in the middle-frequency region of the Nyquist plot are fitted with one or two resistance//pseudo-capacitance elements, to model the charge-transfer and the SEI layer contributions. ${ }^{90-92}$ Complex circuit models, such as transmission line models, involving a much larger number of circuit components, are needed to take into account 
the ionic and electronic paths resistances across composite electrodes, including the contact resistance at the electrode/current collector interface, in addition of the two aforementioned charge-transfer and SEI layer contributions. ${ }^{92}$

For all measurements taken at $0.4,0.15$ and $0.005 \mathrm{~V}$, two apparent contributions are clearly observed and assigned to the SEI and charge transfer resistances. ${ }^{93,94}$ The corresponding circuit model used to fit the experimental data is drawn in Figure S15 and the comparison of these two contributions (the SEI and charge transfer resistances) at $0.4,0.15$ and $0.005 \mathrm{~V}$ for electrodes at pH 2.5, 4 and 6 is given in Figure 8c. For other potentials (OCV and 1 V), the interpretation will take into account the overall resistance of the apparent semi-circle in the middle-frequency region, defined by the difference between its two intersections with the real axis and referred to in the following as the total interfacial resistance. Lastly, the comparison of this total interfacial resistance as a function of measured potential during the first cycle is plotted in Figure $\mathbf{8 b}$ for the three electrodes.

Figure $\mathbf{8 b}$ gives an analysis of the overall resistance obtained with electrodes prepared at $\mathrm{pH}$ 2.5, 4 and 6 and after SEI stabilization. In its pristine state, from the OCV to $0.4 \mathrm{~V}$, the $\mathrm{pH} 6$ electrode shows an overall resistance $(81 \mathrm{Ohm})$ more than twice higher than the value for $\mathrm{pH} 2.5$ and $\mathrm{pH} 4$ electrodes, $\sim 36 \mathrm{Ohm}$ and $\sim 39 \mathrm{Ohm}$, respectively. We attribute the higher total resistance of $\mathrm{pH} 6$ to the pre-formed artificial $\mathrm{PAAH}_{1-\mathrm{x}} \mathrm{Li}_{\mathrm{x}}$-based SEI layer that is more developed on the silicon surface, as discussed in the previous sections. This is in contrast with the $\mathrm{pH} 2.5$ electrode, for which according to NMR, a high amount of SEI is present at the surface of the active material before cycling but seems less resistive than the $\mathrm{PAAH}_{1-\mathrm{x}} \mathrm{Li}_{\mathrm{x}}$ based $\mathrm{SEI}$. With respect to the initial state, the $\mathrm{pH} 4$ electrode seems to present a behavior closer to that of the $\mathrm{pH} 2.5$ electrode, with an intermediate amount of SEI, that has a limited impact on the interfacial resistance when compared 
to the artificial $\mathrm{PAAH}_{1-\mathrm{x}} \mathrm{Li}_{\mathrm{x}}$ based SEI. When the potential is lowered down to $0.4 \mathrm{~V}$, all the electrodes see their overall resistance decrease significantly (by 25\% in all cases), which may be related to the permeability to the electrolyte of the binder layers. Deconvolution of the total interfacial resistance in $\mathrm{R}_{\mathrm{SEI}}$ and $\mathrm{R}_{\mathrm{CT}}$ contributions at $0.4,0.15$ and $0.005 \mathrm{~V}$ is given in Figure 8c and reported in Figure $\mathbf{8 b}$. The first contribution, $\mathrm{R}_{\mathrm{SEI}}$, is much higher for the electrode prepared at pH 6, which underlines again the role of pre-formed artificial SEI played by the binder phase as it more homogeneously covers the Si and Gr active mass surface.

For all the electrodes, the resistance decreases from $0.4 \mathrm{~V}$ with the lithiation of the silicon, as already observed. ${ }^{91}$ This is due to the progressive $\mathrm{R}_{\mathrm{CT}}$ decrease for all electrodes along the lithiation process. On the one hand, it could be attributed to an improvement in electronic transfers between the particles in the electrode and with the current collector, following the increase in internal pressure inside the electrochemical cell, as a result of significant silicon expansion in a closed space which led to a decrease in contact resistance. On the other hand, the electronic conductivity of silicon increases with the extent of lithium alloying, resulting typically in a lower resistance. ${ }^{95}$ The lowest $\mathrm{R}_{\mathrm{CT}}$ obtained constantly in the case of $\mathrm{pH} 6$ could be explained assuming a larger amount of available lithium near the interface thanks to the polymer binder prelithiation that may help to promote the charge transfer process.

Interestingly, the total interfacial resistance difference between $\mathrm{pH} 6$ and other $\mathrm{pHs}$ becomes negligible when the potential reaches down to $0.15 \mathrm{~V}$ and then to $0.005 \mathrm{~V}$, where the SEI layer is expected to be well formed and the silicon particles are mostly lithiated. In the particular case of the pH 6 electrode, an efficiently covering artificial PAA-based SEI is present in its pristine state. Nevertheless, due to the existence of weak hydrogen bonds between the binder and the silicon surface, it can be expected that these weak bonds are not strong enough to maintain the 
PAA-based layer well attached to the surface upon the drastic volume variation undergone by silicon particles during the lithiation process. Fresh silicon surface would then be exposed towards electrolyte, in a situation close to those encountered for electrodes prepared at other pHs. Equivalent interfacial resistances were also measured by Hays et al. ${ }^{31}$ in a comparable situation, for partially lithiated Si-based electrodes prepared with PAAH (close to $\mathrm{pH}$ 2.5) or PAALi (close to $\mathrm{pH}$ 6). Here, the $\mathrm{pH} 6$ electrode keeps a highest overall resistance that is mostly a consequence of its highest $\mathrm{R}_{\mathrm{SEI}}$, due to the initial polymer conformation at $\mathrm{pH}$ 6. Although $\mathrm{pH} 6$ electrode offers the lowest $\mathrm{R}_{\mathrm{CT}}$ it cannot balance the significant difference between $\mathrm{R}_{\mathrm{SEI}}$ for the $\mathrm{pH} 6$ electrode and $\mathrm{R}_{\text {SEI }}$ obtained in the case of electrodes prepared at $\mathrm{pH} 2.5$ or 4 . Finally, for $\mathrm{pH} 2.5$ et 4 electrodes, similar resistive behaviors for $\mathrm{R}_{\mathrm{SEI}}$ and $\mathrm{R}_{\mathrm{ct}}$ are observed during the first lithiation, suggesting a negligible impact of the binder neutralization at lower pHs (below pH 4) on electrical properties of the electrode/electrolyte interface.

After charging to $1 \mathrm{~V}$, lower total resistances are noted compared to the initial values obtained at OCV and at $0.4 \mathrm{~V}$ for all electrodes. This is attributable on the one hand to the settlement of the electrode during the first lithiation and subsequent extraction. ${ }^{78}$ As the manufactured electrode is not calendared, the first expansion of the electrode likely introduces a reorganization of the arrangement of the particles submitted to internal compressive stress in a restricted volume. ${ }^{80}$ On the other hand, this first cycle probably abruptly modified the arrangement of the binder in contact with the Si and Gr active mass, which can also influence this overall interfacial resistance value. In the particular case of the electrode produced at $\mathrm{pH} 6$, the state of homogeneous covering of the silicon surface by the binder layer has been probably lost, then resulting in a conformation of the binder closer to the other electrodes than in the initial state. In electrodes produced at acidic 
$\mathrm{pH}$, the electro-lithiation of the binder gives them a chemical composition closer to that of the electrode produced at $\mathrm{pH} 6$.

Finally, at the end of this first cycle, the electrode prepared at $\mathrm{pH} 4$ exhibits a lower overall interfacial resistance that could be due to its lower cracking and better preservation of the electronic wiring of the active mass. ${ }^{89,91,96}$ It is however fairly striking to observe that the total interfacial electrode resistance is barely independent with the amount of LiF precipitated on the active mass. As NMR results assume that $94 \%$ of lithiated species in the SEI correspond to $\mathrm{LiF}$ at the end of first cycle, the overall impedance for each $\mathrm{pH}$ are quite similar although the LiF amount can reach up to $15.7 \%$ of the mass of the electrode for $\mathrm{pH} 2.5$ and $4.1 \%$ for $\mathrm{pH} 6$ (Table 1). This may suggest that $\mathrm{LiF}$ is not as a resistive compound toward $\mathrm{Li}^{+}$transport as presumed or claimed in other works. ${ }^{97}$

In summary, the initial interfacial resistance is much higher for the electrode prepared at $\mathrm{pH}$, which is in agreement with the more uniform coverage of the active particles by the binder and its better SEI artificial properties. For all the electrodes, a clear lowering of the total interfacial resistance with lithiation is observed, which is not completely reversible with delithiation that is attributable in particular to the settlement of the electrode as well as to modifications of the binder (electro-lithiation reaction and evolution of the conformation the surface of silicon particles).

Cyclability - The electrode cycling performance of PAAH (pH 2.5), $\mathrm{PAAH}_{0.85} \mathrm{Li}_{0.15}(\mathrm{pH}$ 4) and $\mathrm{PAAH}_{0.22} \mathrm{Li}_{0.78}$ based ( $\mathrm{pH} \mathrm{6)}$ electrodes are given in Figure 5e. The discharge capacity retention is recorded respectively at $81 \%$, $85 \%$, and $77 \%$ after 40 cycles. Thus, the hierarchy established in the first cycle continues during the following cycles, and we can even note that the electrode prepared at pH 4 stands out more clearly from the others after 40 cycles. 
The electrode surfaces were observed at the end of the $30^{\text {th }}$ cycle, and are shown in Figure 6d-f. Additional comparisons between $1^{\text {st }}$ and $30^{\text {th }}$ cycles at higher magnifications are given in Figure S12. Overall, the number of cracks compared to that recorded at the end of the $1^{\text {st }}$ cycle is reduced for all the electrodes, probably due to the growth of the SEI layer during cycling which can participate in the closing of some cracks. It is however notable to find the same hierarchy as that observed at the end of the $1^{\text {st }}$ cycle, the surface of the electrode prepared at $\mathrm{pH} 4$ being very little cracked while those prepared at $\mathrm{pH} 2.5$ and 6 are more cracked. This observation can be explained by the work of Hernandez et al.. ${ }^{7}$ Their operando observations established that cracks open essentially during the first delithiation in response to the deflation of the electrode (contraction during delithiation). Then these cracks close and reopen in exactly the same place. This work, like that of Vanpeene et al., ${ }^{8}$ clearly established a dependence between the cracking of silicon-based electrodes and the mechanical properties of the polymer binder. Thus, the greater resilience of the electrode prepared with the $\mathrm{PAAH}_{0.85} \mathrm{Li}_{0.15}(\mathrm{pH} 4)$ binder to silicon volume variations undeniably attests that this binder has a combination of different and more optimal mechanical and adhesive properties than the of other binders, PAAH- (pH 2.5) and $\mathrm{PAAH}_{0.22} \mathrm{Li}_{0.78}$ based (pH 6).

As a short summary, the capacity hierarchy observed at first cycle is maintained and amplified after cycling (30 cycles), as well as the presence of cracks at the electrode surface that are however less numerous, probably due to a growth of the SEI layer.

\section{CONCLUSION}

Negative electrodes of high surface capacity were prepared with an equal mixture of silicon and graphite as active material and polyacrylic acid as binder. The influence of the degree of 
neutralization has been studied by comparing $\mathrm{PAAH}, \mathrm{PAAH}_{0.85} \mathrm{Li}_{0.15}$ and $\mathrm{PAAH}_{0.22} \mathrm{Li}_{0.78}$, which imposes different pHs in the electrode slurry, respectively equal to 2.5, 4 and 6 . The amount of water added for the preparation of these slurries was adjusted so as to minimize the differences in rheological properties associated with the differences in conformation of the polymer chains (folded at acidic $\mathrm{pH}$ and deployed at neutral $\mathrm{pH}$ ). As a result, it could be obtained electrodes of equal loadings, with a good distribution of the constituents and similar microstructures at the micrometric scale, except a slightly higher porosity at neutral $\mathrm{pH}$ than at acidic $\mathrm{pH}$. However, very pronounced corrosion of the current collector at $\mathrm{pH} 2.5$ was demonstrated, resulting in the dissemination of $\mathrm{Cu}^{2+}$ ions throughout the volume of this electrode. Based on previous work and our characterizations, plausible differences in microstructure at the molecular scale have been proposed and linked to the different behaviors of the electrodes during their battery cycling as follows:

In the electrode prepared at $\mathrm{pH} 6$, the $\mathrm{PAAH}_{0.22} \mathrm{Li}_{0.78}$ binder would form a thin and uniform layer on the surface of the Si and Gr active mass, playing the role of an artificial SEI layer, which makes it possible to minimize the reduction of the electrolyte during the first cycle and to maximize the ICE. The permeability of the binder layer to the electrolyte before silicon lithiation (attributable to the dissociation of lithium carboxylates on contact with the electrolyte solvent), then its cracking during silicon lithiation, are suggested by EIS measurements and by the potential at which FEC reduction is initiated (higher than at other $\mathrm{pH}$ ). The low mechanical resistance of the dry electrode and its strong cracking during the first electrochemical cycle could be due to the lower adhesion of the binder with the surface of the silicon particles and/or to the already elongated conformation of the polymer chains which would minimize the resistance to elongation during the first lithiation. 
In the electrode prepared at $\mathrm{pH} 2.5$, the binder forms a non-uniform layer on the surface of the Si and Gr active mass. The existence of uncovered zones is proven by the detection by NMR of $\mathrm{SiO}_{\mathrm{x}} \mathrm{F}_{\mathrm{y}}$ compound. The most important degradation of the electrolyte is observed for this electrode. It already occurs significantly when the electrode is simply brought into contact with the electrolyte, which could result from the presence of traces of water in greater quantity. The ICE is the lowest of the 3 electrodes. During the first cycle, this binder is transformed. The electrolithiation of the carboxylic acid functions into lithium carboxylate gives it a molecular structure more similar to that of $\mathrm{PAAH}_{0.22} \mathrm{Li}_{0.78}$. This electrode has the highest mechanical strength in the dry state, which is attributable to a high adhesion of the binder phase with the silicon surface via the establishment of strong covalent bonds and with the current collector via copper carboxylates; and a pronounced physical crosslinking of the binder phase (high density of entanglement associated with the folded conformation of the polymer chains and intra- and inter-chain copper carboxylate bridges). However, this electrode strongly cracks during the first electrochemical cycle, which may refer to a too much rigidity of this binder.

The electrode prepared at $\mathrm{pH} 4$ with $\mathrm{PAAH}_{0.85} \mathrm{Li}_{0.15}$ binder exhibits the best initial capacity and the best cyclability. Its mechanical properties in the dry state are close to those of the electrode prepared at $\mathrm{pH} 2.5$, however, it cracks very little during the first electrochemical cycle, which indicates that this binder has original and optimal intrinsic mechanical properties. It may be explained by a less pronounced physical crosslinking than at $\mathrm{pH} 2.5$ linked to the lower concentration of copper carboxylates and a lower entanglement density. In addition, the degradation of the electrolyte is moderate, identical to that observed by NMR for the electrode prepared at $\mathrm{pH} 6$. As in the electrode prepared at $\mathrm{pH} 2.5$, this binder is transformed also during the first cycle by electro-lithiation of its carboxylic acid functions. 
Finally, our results show that for a silicon/graphite blend with a very high silicon content, the $\mathrm{PAAH}_{0.85} \mathrm{Li}_{0.15}$ binder prepared at $\mathrm{pH} 4$ provides the most efficient mix of mechanical and artificial SEI properties allowing for an initial reversible capacity of $1900 \mathrm{mAh} \mathrm{g}^{-1}$ and an initial coulombic efficiency of 91\%, very exceptional performance metrics never achieved before at high loading superior to $6 \mathrm{mAh} \mathrm{cm}^{-2}$. An important result worth to emphasize is that for the peculiar electrolyte used here based on a mixture of FEC and DMC (without EC), the main degradation product at the end of the $1^{\text {st }}$ cycle, is highly concentrated LiF which appears very beneficial to the SEI conductivity. Lastly, this paper demonstrates there is a considerable stake in optimizing the silicon/graphite blend electrode formulation with the careful selection of the polymeric binders with optimal mechanical/SEI/conformational properties. We hope this work will open new avenues to developing efficient silicon/graphite anodes for the new generation of high energy Liion batteries. 


\section{FIGURES}
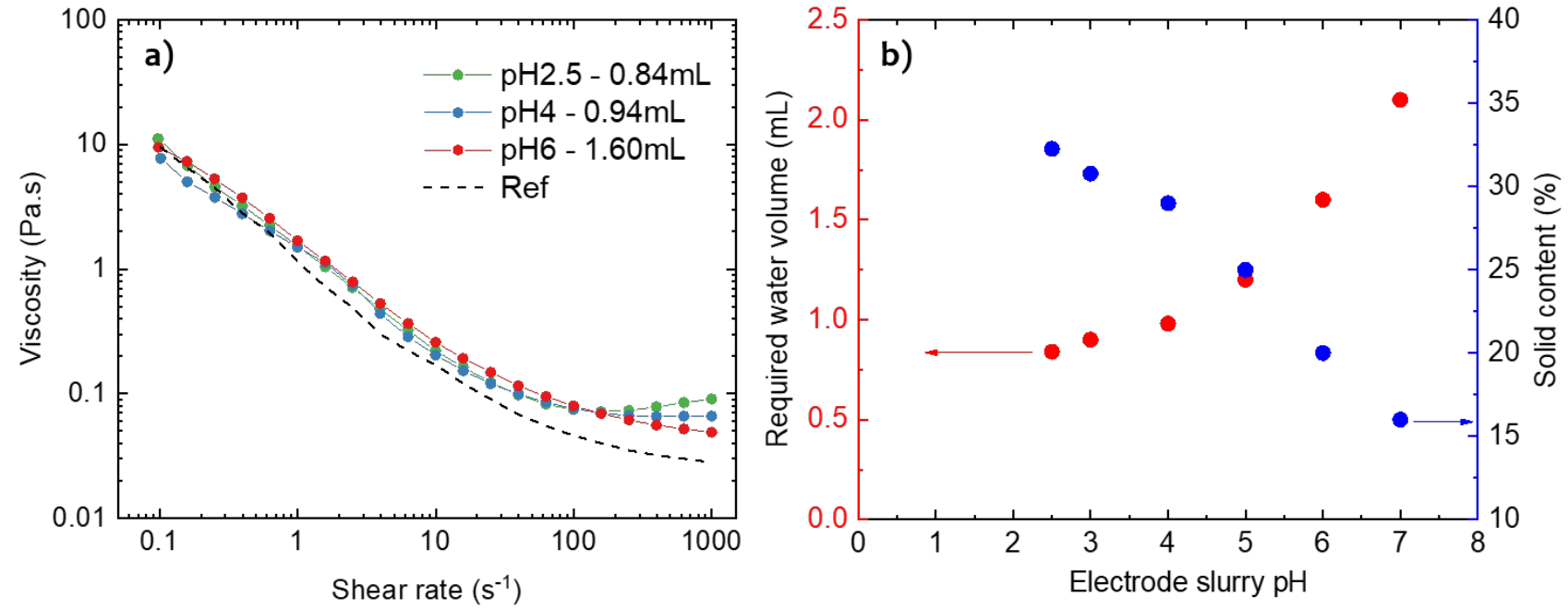

Figure 1. Rheological properties of Si/Gr electrode slurry related to their neutralization degree $\mathrm{x}$ in $\mathrm{PAAH}_{1-\mathrm{x}} \mathrm{Li}_{\mathrm{x}}$ and $\mathrm{pH}$. a) Change of viscosity as a function of the shear rate at $\mathrm{pH} 2.5,4$ and 6 by comparison to the values targeted for an ideal slurry behavior ${ }^{16}$ (dotted line); b) required water volume (for $400 \mathrm{mg}$ electrode materials) and solid content as a function of the $\mathrm{pH}$ of the electrode slurry. 


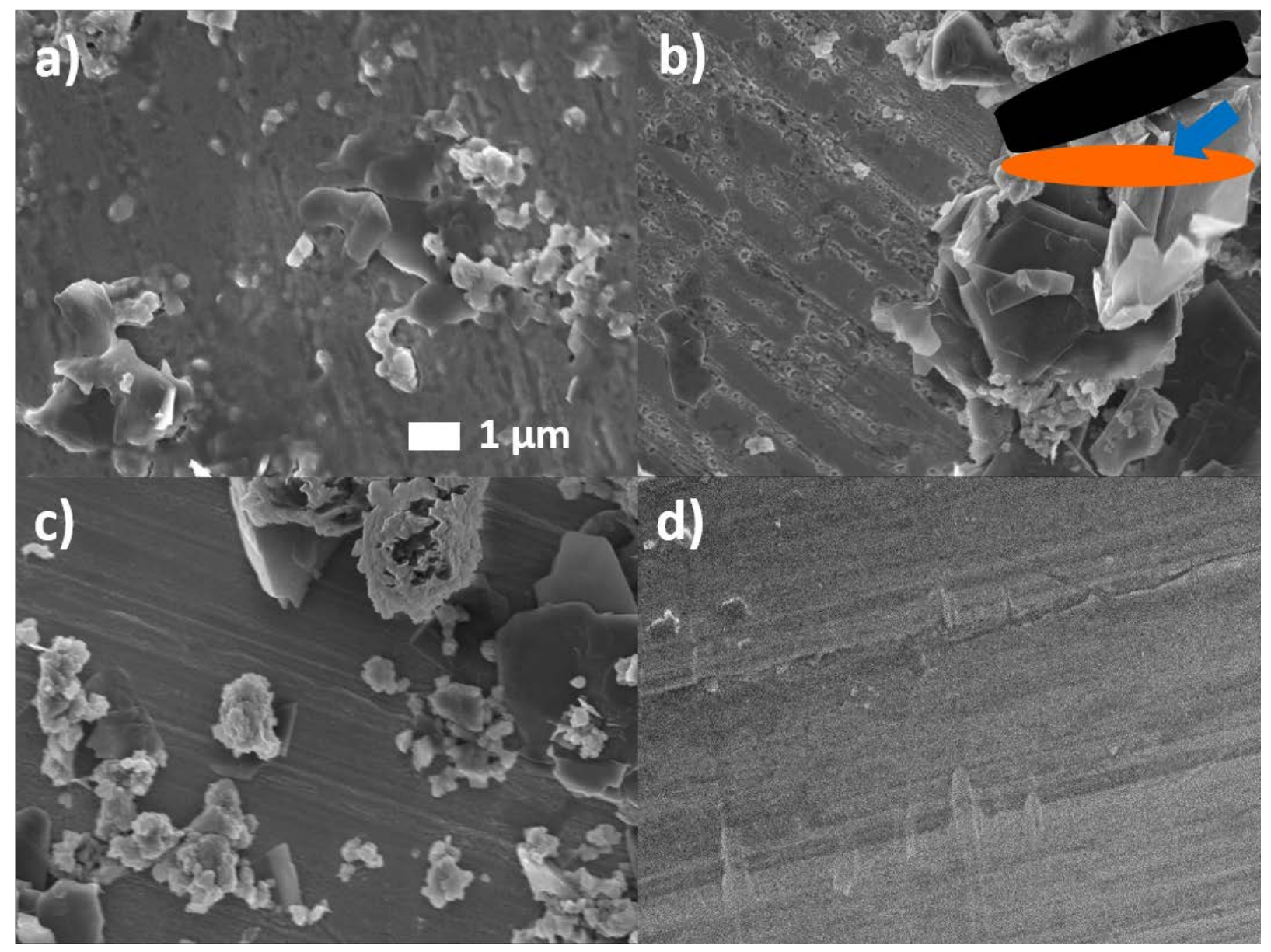

Figure 2. SEM images of the copper substrate after removing the electrode deposit at a) pH2.5; b) at pH4; c) at pH6; and d) pristine copper surface. The scheme represents the current collector (orange), the electrode (black), and the zone explored (blue arrow). Scale bar (shown in a) is the same for all images. 
a)

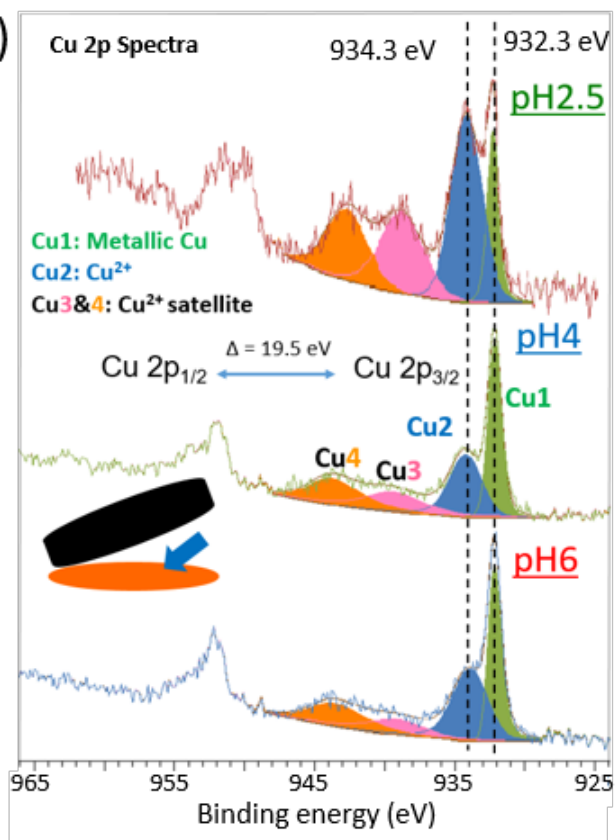

c)

\begin{tabular}{|c:c}
\hline Si 2p Spectra & $102.3 \mathrm{eV}$ \\
\hline & $99.5 \mathrm{eV}$ \\
$\mathrm{pH} 2.5$
\end{tabular}

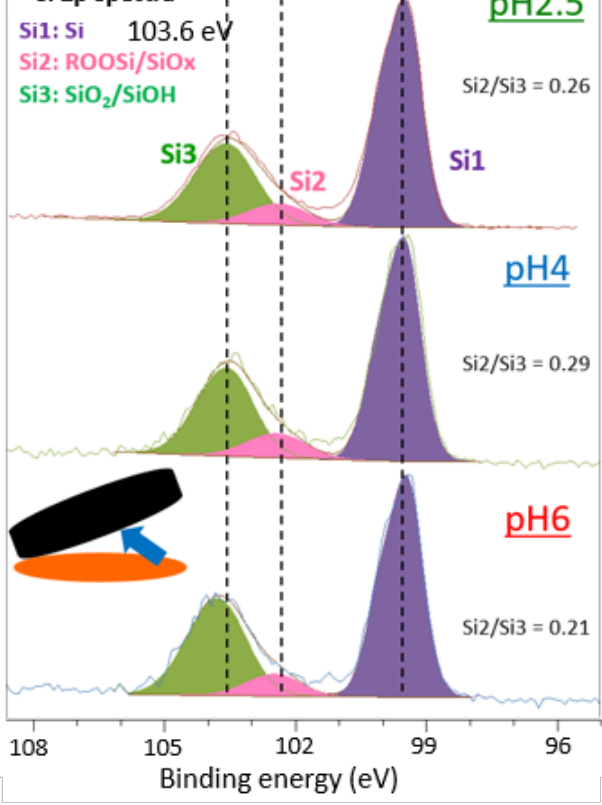

b)

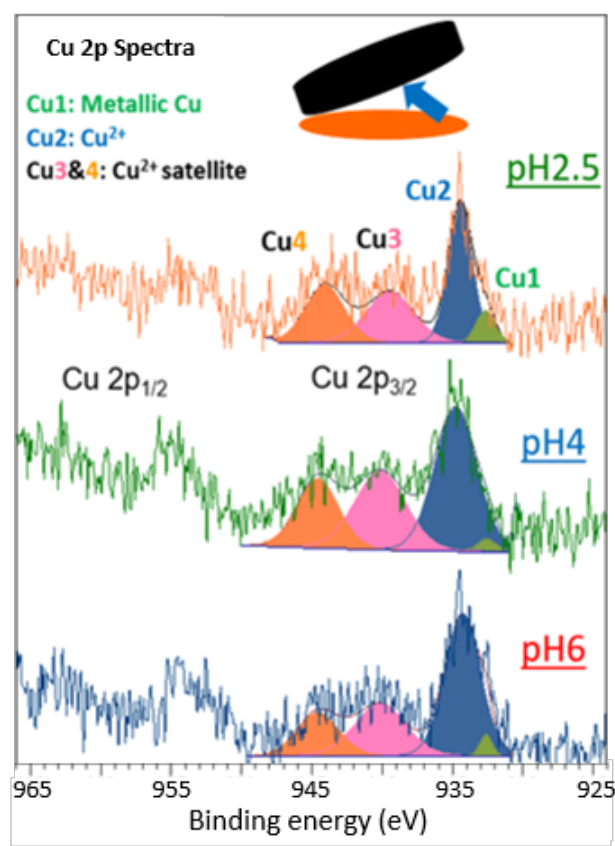

d)

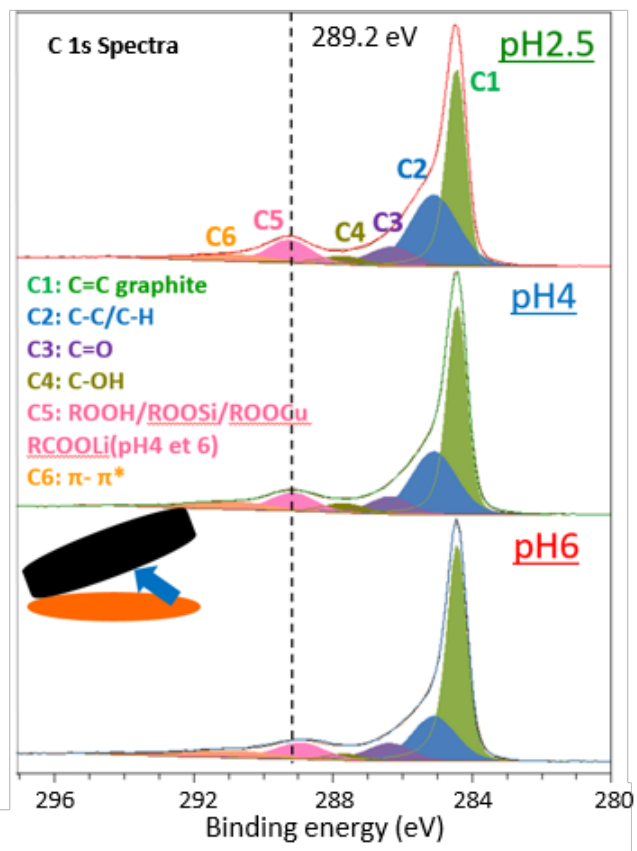

Figure 3. XPS spectra of Si/Gr electrode prepared at $\mathrm{pH}$ 2.5, 4 and 6. $\mathrm{Cu} 2 \mathrm{p}$ core peaks a) on the copper substrate after removing the electrode and b) on the corresponding electrode side; c) Si 2p core peaks on the same electrode side and d) C 1s core peaks on the same electrode side. The scheme represents the current collector (orange), the electrode (black), and the zone explored (blue arrow). 

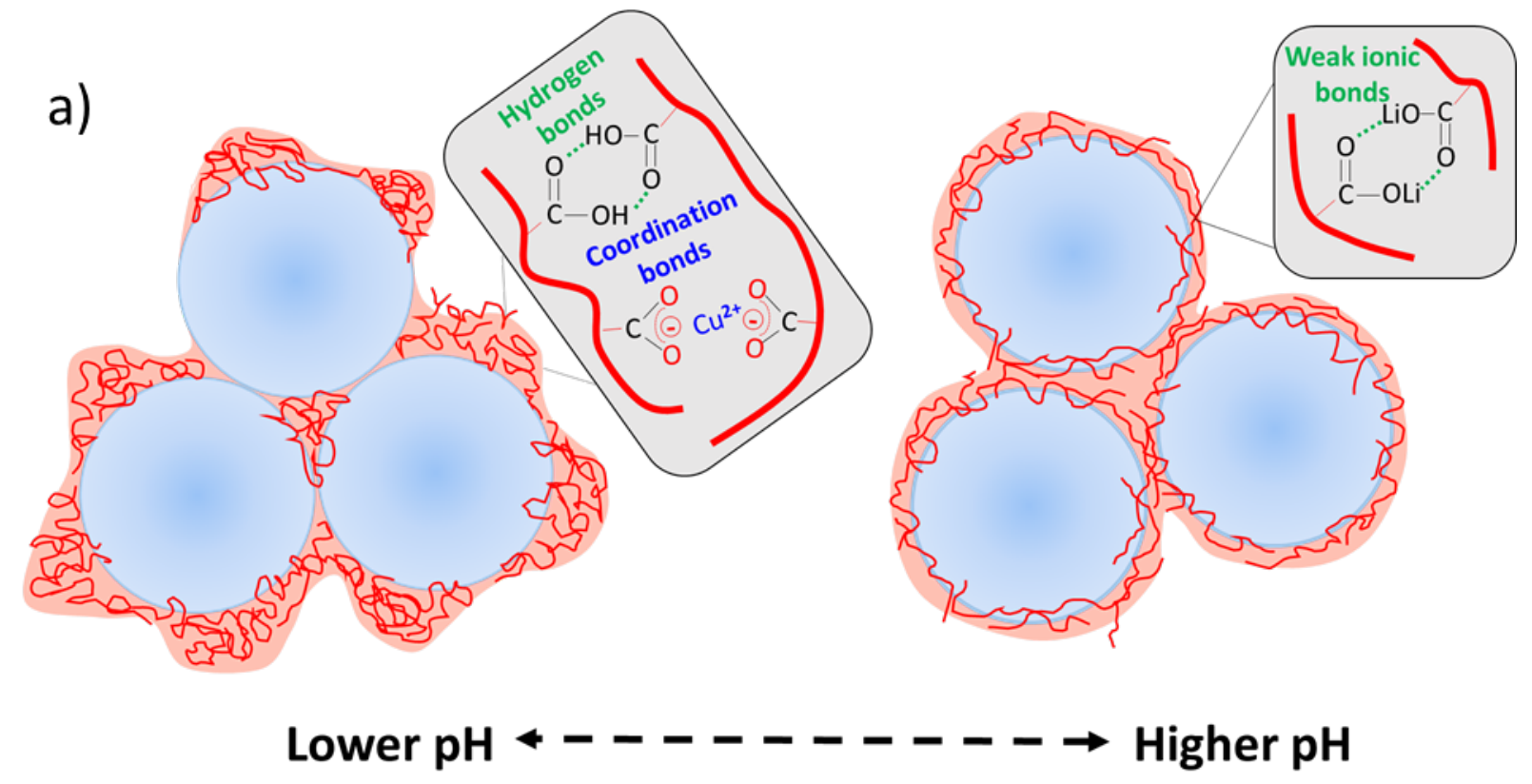

b)

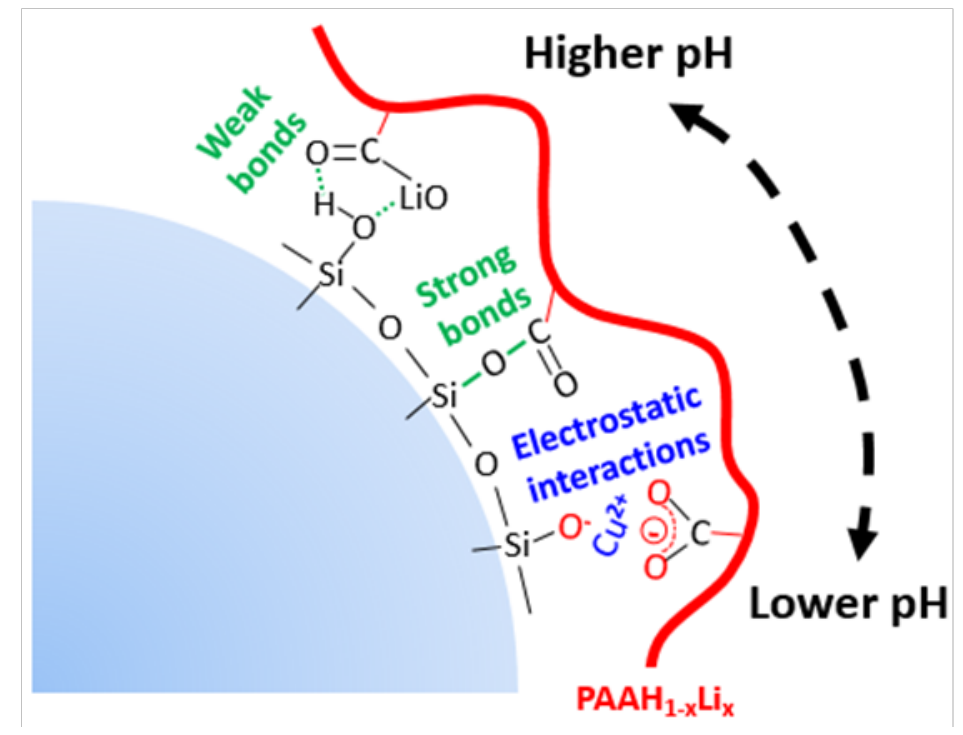

Figure 4. Schematization of a) the different patterns of arrangement of the binder on the surface of the silicon and graphite particles depending on $\mathrm{pH}$ condition in the slurry and b) the different types of bonds with the silicon particles surface. The dotted arrows indicate trends according to the $\mathrm{pH}$ value. For example, there are more coordination bonds and intra- and inter-chain hydrogen bonds at acidic $\mathrm{pH}$ and more bonds between Li carboxylates at neutral $\mathrm{pH}$. 

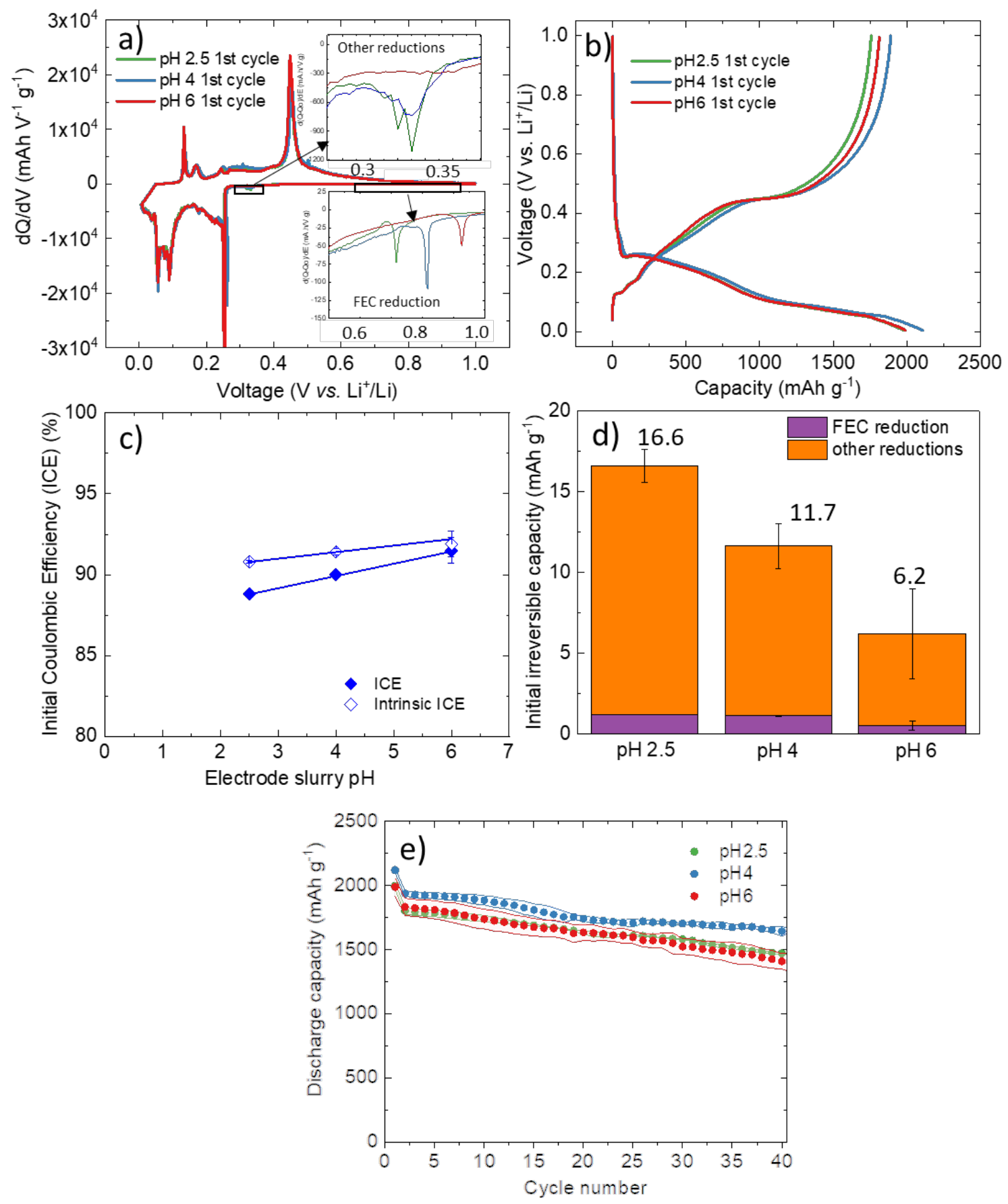

Figure 5. Electrochemical profiles at $1^{\text {st }}$ cycle for electrodes prepared at $\mathrm{pH} 2.5,4$ and 6; a) Incremental capacity-voltage curves; b) Voltage-specific capacity curves; c) ICE and intrinsic ICE (see text); d) FEC electrolyte decomposition electrochemical analysis at first discharge, reduction potential peak (left scale) and resulting irreversible capacity (right scale). e) Electrochemical 
cyclability for electrodes adjusted at $\mathrm{pH} 2.5,4$ and 6 . The discs point to the mean values and the lines give the upper and lower limits of the results acquired on 3 or 4 cells.
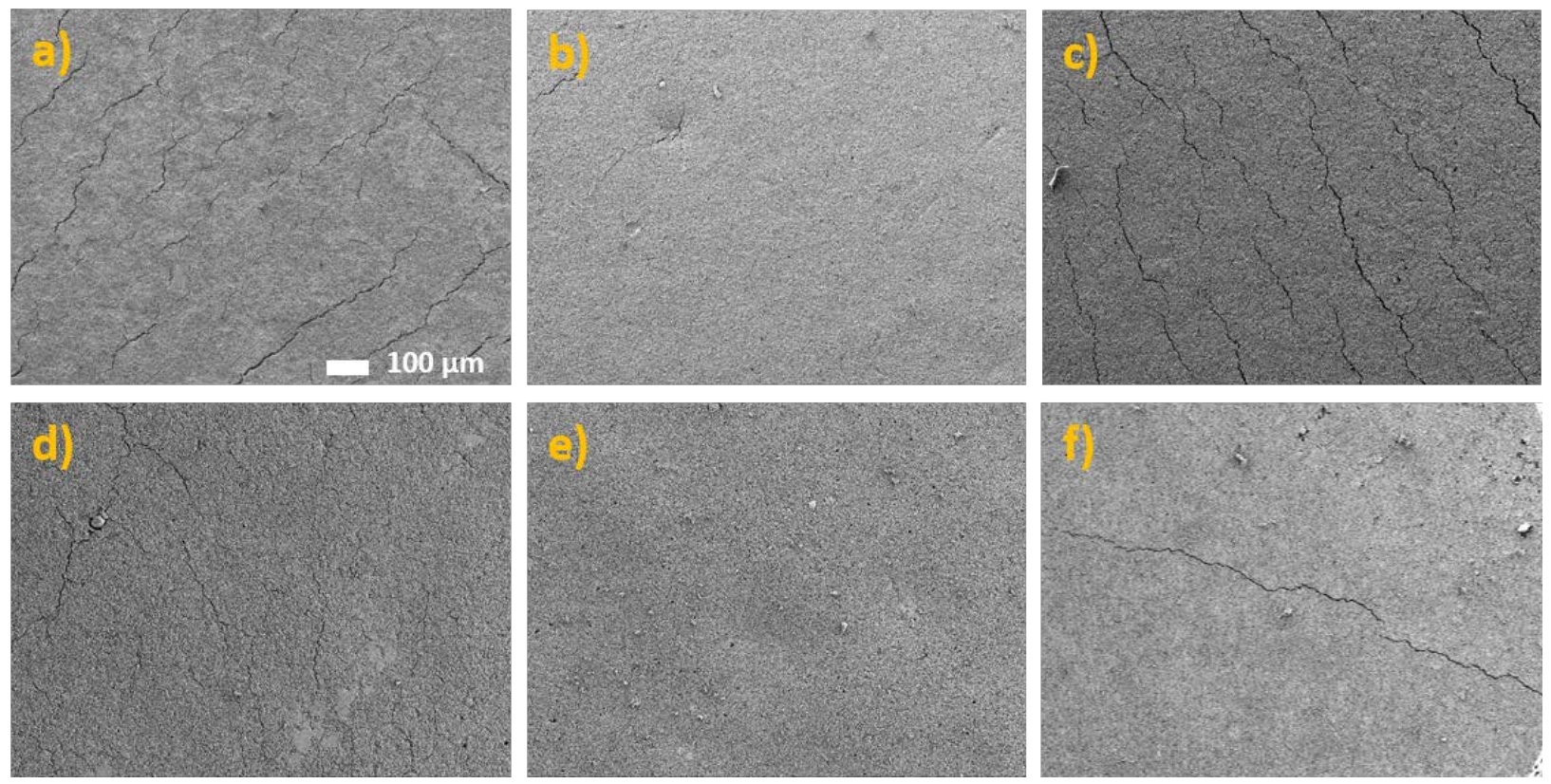

Figure 6. Comparison of morphological behavior of electrode surface after 1 and 30 cycles a,d) at $\mathrm{pH} 2.5$; b,e) at $\mathrm{pH} 4$; c,f) at $\mathrm{pH}$ 6. Larger views will be found in Figure S13. Scale bar (shown in a) is the same for all images. 

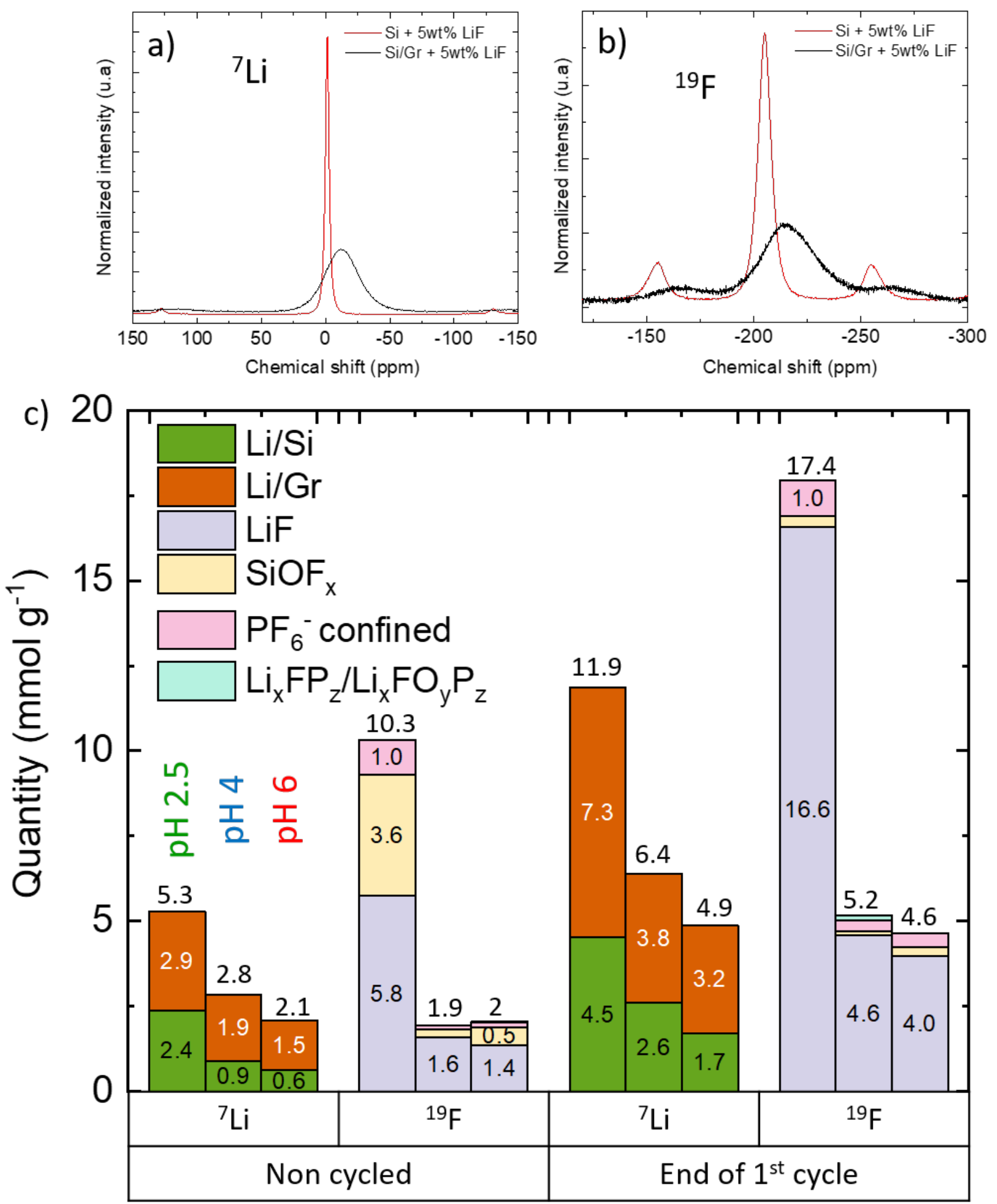
Figure 7. MAS-NMR characterizations of reference materials of $\mathrm{Si}+5 \mathrm{wt} \% \mathrm{LiF}$ and $\mathrm{Si} / \mathrm{Gr}+5 \mathrm{wt} \%$ $\mathrm{LiF}$, for a) ${ }^{7} \mathrm{Li}$ analysis and b) ${ }^{19} \mathrm{~F}$ analysis. The $\mathrm{NMR}{ }^{7} \mathrm{Li}$ and ${ }^{19} \mathrm{~F}$ quantitative results of electrodes adjusted at pH 2.5, 4 and 6 non cycled and after first cycle are shown in c).
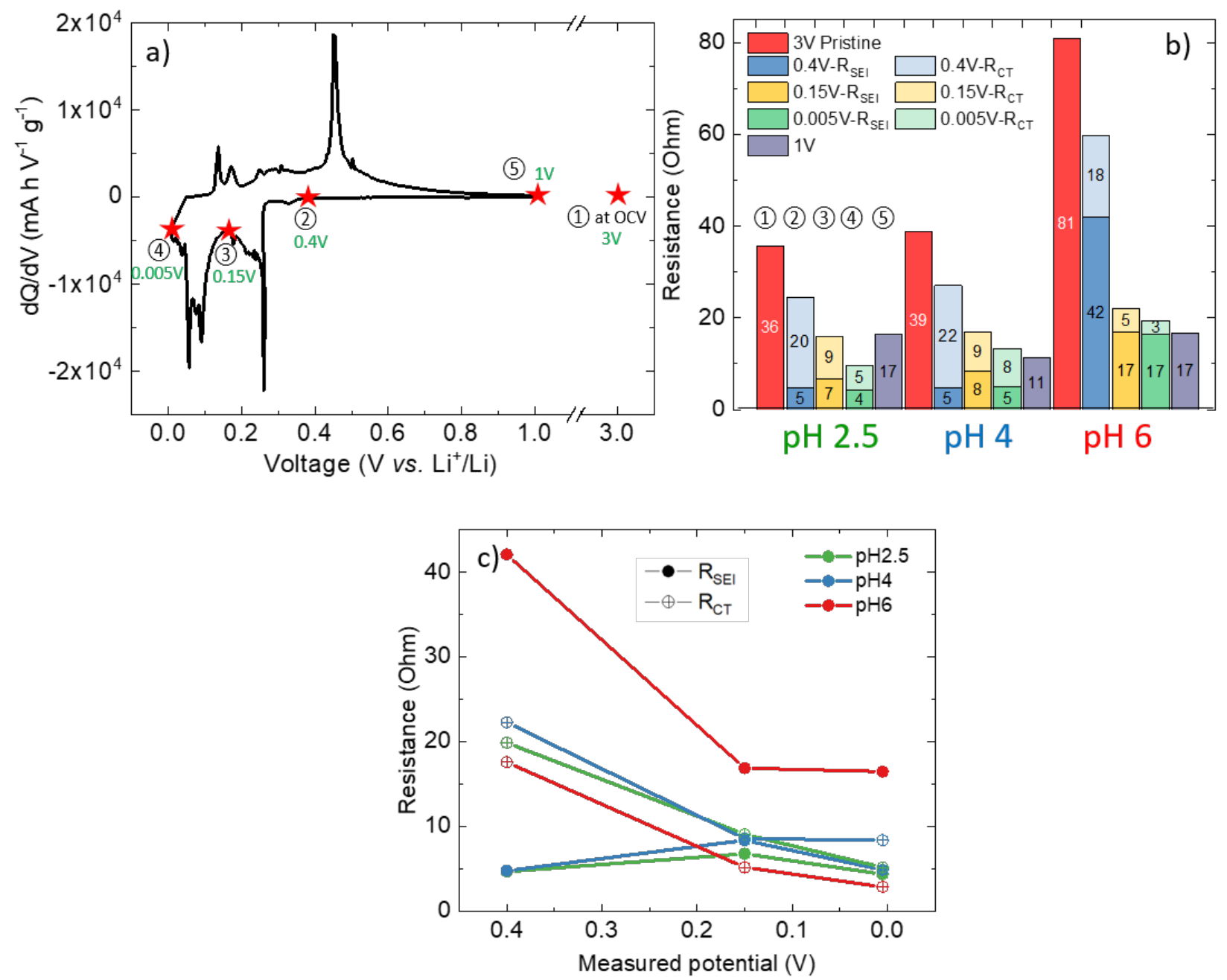

Figure 8. EIS results of electrode adjusted at $\mathrm{pH} 2.5,4$ and 6 at first cycling: a) Taken EIS measurements as a function of discharge/charge profile according to the electroactivities and EIS response at different potentials; b) total interfacial resistance at OCV, 0.4, 0.15, $0.005 \mathrm{~V}$ during $1^{\text {st }}$ lithiation and $1 \mathrm{~V}$ during $1^{\text {st }}$ delithiation; c) R REI and $\mathrm{R}_{\mathrm{CT}}$ at $0.4,0.15,0.005 \mathrm{~V}$. 

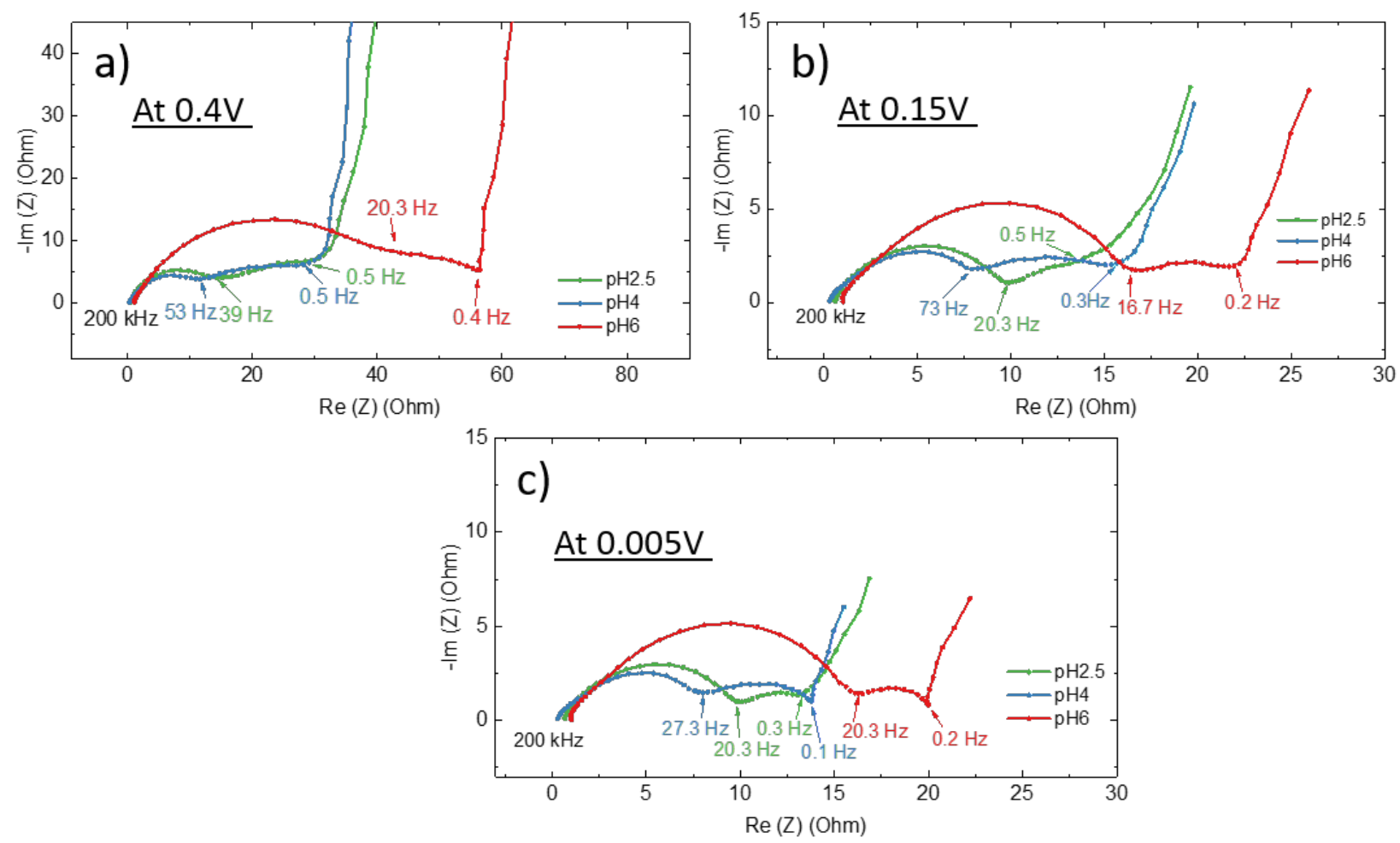

Figure 9. Nyquist plots of EIS acquisition for electrode adjusted at pH2.5, 4 and 6. The measurements were taken during the first lithiation course at a) $0.4 \mathrm{~V}$, b) $0.15 \mathrm{~V}$ and c) $0.005 \mathrm{~V}$. 
TABLES

Table 1. Electrode parameters (loading and porosity); scratch resistance; SEM-EDX (atomic fraction of $\mathrm{Cu}$ ) and XPS chemical quantification of the current collector corrosion; $1^{\text {st }}$ cycle electrochemical data and mass gain. C-rate of $120 / 240 \mathrm{~mA} \mathrm{~g}^{-1}$ (C/16.5 / C/8.3) was used for discharge/charge. Theoretical capacity of as-made Si/Gr electrode is $1975 \mathrm{mAh} \mathrm{g}^{-1}$.

\begin{tabular}{|c|c|c|c|c|c|c|}
\hline $\begin{array}{c}\text { Binder } \\
- \\
\text { pH of electrode } \\
\text { slurry }\end{array}$ & $\begin{array}{l}\text { Active material } \\
\text { (Si/Gr) mass } \\
\text { loading } \\
\left(\mathrm{mg} \mathrm{cm}^{-2}\right) \\
- \\
\text { Porosity (\%) }\end{array}$ & Scratch load (g) & $\begin{array}{c}\text { \%Cu (\%at) in } \\
\text { electrode at } \\
\text { interface with } \\
\text { collector } \\
\text { (SEM-EDX) } \\
\text { - } \\
\text { Ratio Cu }{ }^{2+} / C u \text { at } \\
\text { the interface of } \\
\text { collector side } \\
\text { (XPS) }\end{array}$ & $\begin{array}{c}\text { Capacity at } 1^{\text {st }} \text { cycle } \\
\left(\mathrm{mAh} \mathrm{g}^{-1}\right) \\
\text { Discharge } \\
\text { Charge } \\
\text { - } \\
\text { Reversible areal } \\
\text { capacity } \\
\left(\mathrm{mAh} \mathrm{cm}{ }^{-2}\right)\end{array}$ & $\begin{array}{c}\text { Initial Coulombic } \\
\text { efficiency (\%) } \\
\text { Total } \\
- \\
\text { Intrinsic }\end{array}$ & $\begin{array}{c}\text { Mass gain after } 1^{\text {st }} \\
\text { cycle (\%) }\end{array}$ \\
\hline $\begin{array}{c}\text { PAAH } \\
- \\
2.5\end{array}$ & $\begin{array}{c}3.3 \pm 0.2 \\
- \\
57 \pm 3\end{array}$ & $400<x<450$ & $\begin{array}{c}3.53 \% \\
- \\
5.5\end{array}$ & $\begin{array}{c}2000 \pm 30 \\
1780 \pm 30 \\
- \\
5.9 \pm 0.1\end{array}$ & $\begin{array}{c}88.8 \pm 0.1 \\
- \\
90.8 \pm 0.1\end{array}$ & 15.7 \\
\hline $\begin{array}{c}\mathrm{PAAH}_{0.85} \mathrm{Li}_{0.15} \\
- \\
4.0\end{array}$ & $\begin{array}{c}3.4 \pm 0.2 \\
- \\
62 \pm 2\end{array}$ & $350<x<400$ & $\begin{array}{c}0.27 \% \\
- \\
2.2\end{array}$ & $\begin{array}{c}2120 \pm 20 \\
1910 \pm 20 \\
- \\
6.5 \pm 0.1\end{array}$ & $\begin{array}{c}90.0 \pm 0.2 \\
- \\
91.4 \pm 0.2\end{array}$ & 5.5 \\
\hline $\begin{array}{c}\mathrm{PAAH}_{0.22} \mathrm{Li}_{0.78} \\
- \\
6.0\end{array}$ & $\begin{array}{c}3.3 \pm 0.2 \\
- \\
63 \pm 1\end{array}$ & $150<x<200$ & $\begin{array}{c}0.15 \% \\
- \\
2.1\end{array}$ & $\begin{array}{c}1990 \pm 70 \\
1820 \pm 80 \\
- \\
6.0 \pm 0.3\end{array}$ & $\begin{array}{c}91.5 \pm 0.8 \\
- \\
91.9 \pm 0.8\end{array}$ & 4.1 \\
\hline
\end{tabular}


Table 2. Total irreversible capacity at first cycle of electrodes prepared at $\mathrm{pH}$ 2.5, 4 and 6 and their partially respective contributions owing to PAA electro-lithiation, FEC and other reductions.

\begin{tabular}{|c|c|c|c|c|}
\hline $\begin{array}{c}\text { Binder } \\
\text { pH of electrode slurry }\end{array}$ & $\begin{array}{c}\text { PAA electro-lithiation } \\
\left(\mathrm{mAh} \mathrm{g}^{-1}\right)\end{array}$ & $\begin{array}{c}\text { FEC reduction } \\
\left(\mathrm{mAh} \mathrm{g}^{-1}\right)\end{array}$ & $\begin{array}{c}\text { Total irreversible } \\
\text { other reductions } \\
\left(\mathrm{mAh} \mathrm{g}^{-1}\right)\end{array}$ & $\begin{array}{c}\text { capacity at lithiation } \\
\left(\mathrm{mAh} \mathrm{g}^{-1}\right)\end{array}$ \\
\hline PAAH & 43.3 & $1.21 \pm 0.02$ & $222 \pm 2$ \\
\hline PAAH $_{0.85} \mathrm{Li}_{0.15}$ & 36.3 & $1.15 \pm 0.03$ & $10.5 \pm 1.4$ & $213 \pm 4$ \\
\hline 4.0 & 9.0 & $0.52 \pm 0.27$ & $5.7 \pm 2.8$ & $170 \pm 9$ \\
\hline PAAH
\end{tabular}


Table 3. NMR quantitative comparison in terms of LiF and other Li diamagnetic components. LiF quantification refers to the total electrode mass after cell disassembly.

\begin{tabular}{|c|c|c|c|c|}
\hline \multirow[b]{2}{*}{$\begin{array}{c}\text { Electrode slurry } \mathrm{pH} \\
\text { control }\end{array}$} & \multicolumn{2}{|c|}{ Non cycled } & \multicolumn{2}{|c|}{ End of $1^{\text {st }}$ charge } \\
\hline & $\begin{array}{c}\text { Quantity of LiF } \\
\left(\mathrm{mmol} \mathrm{g}^{-1}\right)\end{array}$ & $\begin{array}{l}\text { Quantity of other Li dia } \\
\qquad\left(\mathrm{mmol} \mathrm{g}^{-1}\right) \\
\text { \%Li dia in the whole SEI }\end{array}$ & $\begin{array}{c}\text { Quantity of LiF } \\
\left(\mathrm{mmol} \mathrm{g}^{-1}\right) \\
\text { \%LiF in the whole SEI }\end{array}$ & $\begin{array}{l}\text { Quantity of other Li dia } \\
\qquad\left(\mathrm{mmol} \mathrm{g}^{-1}\right) \\
\text { \%Li dia in the whole SEI }\end{array}$ \\
\hline 2.5 & $\begin{array}{c}5.3 \\
100 \%\end{array}$ & $\begin{array}{c}0 \\
0 \%\end{array}$ & $\begin{array}{c}11.9 \\
100 \%\end{array}$ & $\begin{array}{c}0 \\
0 \%\end{array}$ \\
\hline 4 & $\begin{array}{l}1.9 \\
68 \%\end{array}$ & $\begin{array}{c}0.9 \\
32 \%\end{array}$ & $\begin{array}{l}5.2 \\
81 \%\end{array}$ & $\begin{array}{l}1.2 \\
19 \%\end{array}$ \\
\hline 6 & $\begin{array}{c}2 \\
95 \%\end{array}$ & $\begin{array}{l}0.1 \\
5 \%\end{array}$ & $\begin{array}{l}4.6 \\
94 \%\end{array}$ & $\begin{array}{l}0.3 \\
6 \%\end{array}$ \\
\hline
\end{tabular}




\section{Supporting Information.}

Polymer solution $\mathrm{pH}$ titration; dynamic modulus of electrode slurry; copper species Pourbaix Diagram; SEM images of interface at electrode side or on the top of electrode surface; XPS full spectra; statistical micro-Raman analysis on silicon particles; electrochemical analysis of peak at 0.4-0.3V; SEM images after 1 and 30 cycles; NMR spectra; EIS Nyquist plots; calculations of the intrinsic ICE.

\section{AUTHOR INFORMATION}

\section{Corresponding Author}

Bernard Lestriez - Université de Nantes, CNRS, Institut des Matériaux Jean Rouxel, IMN, F-44000 Nantes, France ; Email : bernard.lestriez@univ-nantes.fr

\section{Present Addresses}

Driss Mazouzi - Materials, Natural Substances, Environment and Modeling Laboratory. Multidisciplinary Faculty of Taza. University of Sidi Mohamed Ben Abdellah, Fes, Morocco

Lionel Roué - Institut National de la Recherche Scientifique (INRS) - Centre Énergie, Matériaux, Télécommunications (EMT), J3X 1S2 Varennes (QC) Canada

\section{Author Contributions}

Jianhan Xiong: Conceptualization, Investigation, Writing - original draft. Nicolas Dupré: Conceptualization, Investigation, Writing - review \& editing. Driss Mazouzi: review \& editing. Dominique Guyomard: review \& editing. Lionel Roué: Conceptualization, review \& editing. Bernard Lestriez: Conceptualization, writing - review \& editing. All authors have given approval to the final version of the manuscript. 


\section{Funding Sources}

Agence Nationale de la Recherche (ANR) funding for the SILMARILION project (ANR-16CE05-0015).

\section{Notes}

The authors declare no competing financial interest.

\section{ACKNOWLEDGMENT}

We are grateful to M. Chakir, L. Croguennec, C. Tessier, M. Ulldemolins, and B. Mortemard de Boisse for the fruitful discussions. R. Grissa and J. Hamon are warmly thanked for their helps in XPS measurements. N. Stephant is acknowledged for the SEM images acquisitions. 


\section{REFERENCES}

(1) Obrovac, M. N.; Christensen, L.; Le, D. B.; Dahn, J. R. Alloy Design for Lithium-Ion Battery Anodes. J. Electrochem. Soc. 2007, 154 (9), A849. https://doi.org/10.1149/1.2752985.

(2) Obrovac, M. N.; Chevrier, V. L. Alloy Negative Electrodes for Li-Ion Batteries. Chem. Rev. 2014, 114 (23), 11444-11502. https://doi.org/10.1021/cr500207g.

(3) Obrovac, M. N. Si-Alloy Negative Electrodes for Li-Ion Batteries. Curr. Opin. Electrochem. 2018, 9, 8-17. https://doi.org/10.1016/j.coelec.2018.02.002.

(4) Zuo, X.; Zhu, J.; Müller-Buschbaum, P.; Cheng, Y.-J. Silicon Based Lithium-Ion Battery Anodes: A Chronicle Perspective Review. Nano Energy 2017, 31, 113-143. https://doi.org/10.1016/j.nanoen.2016.11.013.

(5) McDowell, M. T.; Lee, S. W.; Harris, J. T.; Korgel, B. A.; Wang, C.; Nix, W. D.; Cui, Y. In Situ TEM of Two-Phase Lithiation of Amorphous Silicon Nanospheres. Nano Lett. 2013, 13 (2), 758-764. https://doi.org/10.1021/nl3044508.

(6) Tranchot, A.; Idrissi, H.; Thivel, P.-X.; Roué, L. Influence of the Si Particle Size on the Mechanical Stability of Si-Based Electrodes Evaluated by in-Operando Dilatometry and Acoustic Emission. J. Power Sources 2016, 330, 253-260. https://doi.org/10.1016/j.jpowsour.2016.09.017.

(7) Hernandez, C. R.; Etiemble, A.; Douillard, T.; Mazouzi, D.; Karkar, Z.; Maire, E.; Guyomard, D.; Lestriez, B.; Roué, L. A Facile and Very Effective Method to Enhance the Mechanical Strength and the Cyclability of Si-Based Electrodes for Li-Ion Batteries. Adv. Energy Mater. 2018, 8 (6), 1701787. https://doi.org/10.1002/aenm.201701787.

(8) Vanpeene, V.; Villanova, J.; King, A.; Lestriez, B.; Maire, E.; Roué, L. Dynamics of the Morphological Degradation of Si-Based Anodes for Li-Ion Batteries Characterized by In Situ Synchrotron X-Ray Tomography. Adv. Energy Mater. 2019, 9 (18), 1803947. https://doi.org/10.1002/aenm.201803947.

(9) Li, Q.; Liu, X.; Han, X.; Xiang, Y.; Zhong, G.; Wang, J.; Zheng, B.; Zhou, J.; Yang, Y. Identification of the Solid Electrolyte Interface on the Si/C Composite Anode with FEC as the Additive. ACS Appl. Mater. Interfaces 2019, 11 (15), 14066-14075. https://doi.org/10.1021/acsami.8b22221.

(10) Markevich, E.; Salitra, G.; Aurbach, D. Fluoroethylene Carbonate as an Important Component for the Formation of an Effective Solid Electrolyte Interphase on Anodes and Cathodes for Advanced Li-Ion Batteries. ACS Energy Lett. 2017, 2 (6), 1337-1345. https://doi.org/10.1021/acsenergylett.7b00163.

(11) Eshetu, G. G.; Figgemeier, E. Confronting the Challenges of Next-Generation Silicon Anode-Based Lithium-Ion Batteries: Role of Designer Electrolyte Additives and Polymeric Binders. ChemSusChem 2019, 12 (12), 2515-2539. https://doi.org/10.1002/cssc.201900209.

(12) Li, P.; Kim, H.; Myung, S.-T.; Sun, Y.-K. Diverting Exploration of Silicon Anode into Practical Way: A Review Focused on Silicon-Graphite Composite for Lithium Ion Batteries. Energy Storage Mater. 2020. https://doi.org/10.1016/j.ensm.2020.11.028. Armand, M.; Axmann, P.; Bresser, D.; Copley, M.; Edström, K.; Ekberg, C.; Guyomard, D.; Lestriez, B.; Novák, P.; Petranikova, M.; Porcher, W.; Trabesinger, S.; WohlfahrtMehrens, M.; Zhang, H. Lithium-Ion Batteries - Current State of the Art and Anticipated 
Developments. J. Power Sources 2020, 479, 228708.

https://doi.org/10.1016/j.jpowsour.2020.228708.

(14) Mazouzi, D.; Karkar, Z.; Reale Hernandez, C.; Jimenez Manero, P.; Guyomard, D.; Roué, L.; Lestriez, B. Critical Roles of Binders and Formulation at Multiscales of Silicon-Based Composite Electrodes. J. Power Sources 2015, 280, 533-549. https://doi.org/10.1016/j.jpowsour.2015.01.140.

(15) Wu, J.; Cao, Y.; Zhao, H.; Mao, J.; Guo, Z. The Critical Role of Carbon in Marrying Silicon and Graphite Anodes for High-energy Lithium-ion Batteries. Carbon Energy 2019, 1 (1), 57-76. https://doi.org/10.1002/cey2.2.

(16) Karkar, Z.; Mazouzi, D.; Hernandez, C. R.; Guyomard, D.; Roué, L.; Lestriez, B. Threshold-like Dependence of Silicon-Based Electrode Performance on Active Mass Loading and Nature of Carbon Conductive Additive. Electrochimica Acta 2016, 215, 276-288. https://doi.org/10.1016/j.electacta.2016.08.118.

(17) Bresser, D.; Buchholz, D.; Moretti, A.; Varzi, A.; Passerini, S. Alternative Binders for Sustainable Electrochemical Energy Storage - the Transition to Aqueous Electrode Processing and Bio-Derived Polymers. Energy Environ. Sci. 2018, 11 (11), 3096-3127. https://doi.org/10.1039/C8EE00640G.

(18) Chen, H.; Ling, M.; Hencz, L.; Ling, H. Y.; Li, G.; Lin, Z.; Liu, G.; Zhang, S. Exploring Chemical, Mechanical, and Electrical Functionalities of Binders for Advanced EnergyStorage Devices. Chem. Rev. 2018, 118 (18), 8936-8982. https://doi.org/10.1021/acs.chemrev.8b00241.

(19) Li, J.-T.; Wu, Z.-Y.; Lu, Y.-Q.; Zhou, Y.; Huang, Q.-S.; Huang, L.; Sun, S.-G. Water Soluble Binder, an Electrochemical Performance Booster for Electrode Materials with High Energy Density. Adv. Energy Mater. 2017, 7 (24), 1701185. https://doi.org/10.1002/aenm.201701185.

(20) Young, B. T.; Nguyen, C. C.; Lobach, A.; Heskett, D. R.; Woicik, J. C.; Lucht, B. L. Role of Binders in Solid Electrolyte Interphase Formation in Lithium Ion Batteries Studied with Hard X-Ray Photoelectron Spectroscopy. J. Mater. Res. 2019, 34 (1), 97106. https://doi.org/10.1557/jmr.2018.363.

(21) Yabuuchi, N.; Shimomura, K.; Shimbe, Y.; Ozeki, T.; Son, J.-Y.; Oji, H.; Katayama, Y.; Miura, T.; Komaba, S. Graphite-Silicon-Polyacrylate Negative Electrodes in Ionic Liquid Electrolyte for Safer Rechargeable Li-Ion Batteries. Adv Energy Mater 2011, 7.

(22) Son, Y.; Kim, N.; Lee, T.; Lee, Y.; Ma, J.; Chae, S.; Sung, J.; Cha, H.; Yoo, Y.; Cho, J. Calendering-Compatible Macroporous Architecture for Silicon-Graphite Composite toward High-Energy Lithium-Ion Batteries. Adv. Mater. 2020, 2003286. https://doi.org/10.1002/adma.202003286.

(23) Du, Z.; Dunlap, R. A.; Obrovac, M. N. High Energy Density Calendered Si Alloy/Graphite Anodes. J. Electrochem. Soc. 2014, 161 (10), A1698-A1705. https://doi.org/10.1149/2.0941410jes.

(24) Profatilova, I.; De Vito, E.; Genies, S.; Vincens, C.; Gutel, E.; Fanget, O.; Martin, A.; Chandesris, M.; Tulodziecki, M.; Porcher, W. Impact of Silicon/Graphite Composite Electrode Porosity on the Cycle Life of 18650 Lithium-Ion Cell. ACS Appl. Energy Mater. 2020, acsaem.0c01999. https://doi.org/10.1021/acsaem.0c01999.

(25) Han, J.; Tang, D.-M.; Kong, D.; Chen, F.; Xiao, J.; Zhao, Z.; Pan, S.; Wu, S.; Yang, Q.H. A Thick yet Dense Silicon Anode with Enhanced Interface Stability in Lithium 
Storage Evidenced by in Situ TEM Observations. Sci. Bull. 2020, S2095927320303194. https://doi.org/10.1016/j.scib.2020.05.018.

(26) Karkar, Z.; Guyomard, D.; Roué, L.; Lestriez, B. A Comparative Study of Polyacrylic Acid (PAA) and Carboxymethyl Cellulose (CMC) Binders for Si-Based Electrodes. Electrochimica Acta 2017, 258, 453-466. https://doi.org/10.1016/j.electacta.2017.11.082.

(27) Lestriez, B.; Bahri, S.; Sandu, I.; Roue, L.; Guyomard, D. On the Binding Mechanism of CMC in Si Negative Electrodes for Li-Ion Batteries. Electrochem. Commun. 2007, 9 (12), 2801-2806. https://doi.org/10.1016/j.elecom.2007.10.001.

(28) Magasinski, A.; Zdyrko, B.; Kovalenko, I.; Hertzberg, B.; Burtovyy, R.; Huebner, C. F.; Fuller, T. F.; Luzinov, I.; Yushin, G. Toward Efficient Binders for Li-Ion Battery SiBased Anodes: Polyacrylic Acid. ACS Appl. Mater. Interfaces 2010, 2 (11), 3004-3010. https://doi.org/10.1021/am100871y.

(29) Porcher, W.; Chazelle, S.; Boulineau, A.; Mariage, N.; Alper, J. P.; Van Rompaey, T.; Bridel, J.-S.; Haon, C. Understanding Polyacrylic Acid and Lithium Polyacrylate Binder Behavior in Silicon Based Electrodes for Li-Ion Batteries. J. Electrochem. Soc. 2017, 164 (14), A3633-A3640. https://doi.org/10.1149/2.0821714jes.

(30) Aoki, S.; Han, Z.-J.; Yamagiwa, K.; Yabuuchi, N.; Murase, M.; Okamoto, K.; Kiyosu, T.; Satoh, M.; Komaba, S. Acrylic Acid-Based Copolymers as Functional Binder for Silicon/Graphite Composite Electrode in Lithium-Ion Batteries. J. Electrochem. Soc. 2015, 162 (12), A2245-A2249. https://doi.org/10.1149/2.0171512jes.

(31) Hays, K. A.; Ruther, R. E.; Kukay, A. J.; Cao, P.; Saito, T.; Wood, D. L.; Li, J. What Makes Lithium Substituted Polyacrylic Acid a Better Binder than Polyacrylic Acid for Silicon-Graphite Composite Anodes? J. Power Sources 2018, 384, 136-144. https://doi.org/10.1016/j.jpowsour.2018.02.085.

(32) Sung, S. H.; Kim, D. H.; Kim, S.; Jeong, M. H.; Nam, J.; Ahn, K. H. Effect of Neutralization of Poly(Acrylic Acid) Binder on the Dispersion Heterogeneity of Li-Ion Battery Electrodes. J. Mater. Sci. 2019, 54 (20), 13208-13220. https://doi.org/10.1007/s10853-019-03846-5.

(33) Burdette-Trofimov, M. K.; Armstrong, B. L.; Rogers, A. M.; Heroux, L.; Doucet, M.; Yang, G.; Phillip, N. D.; Kidder, M. K.; Veith, G. M. Understanding Binder-Silicon Interactions during Slurry Processing. J. Phys. Chem. C 2020, 124 (24), 13479-13494. https://doi.org/10.1021/acs.jpcc.0c03660.

(34) Hu, B.; Jiang, S.; Shkrob, I. A.; Zhang, J.; Trask, S. E.; Polzin, B. J.; Jansen, A.; Chen, W.; Liao, C.; Zhang, Z.; Zhang, L. Understanding of Pre-Lithiation of Poly(Acrylic Acid) Binder: Striking the Balances between the Cycling Performance and Slurry Stability for Silicon-Graphite Composite Electrodes in Li-Ion Batteries. J. Power Sources 2019, 416, 125-131. https://doi.org/10.1016/j.jpowsour.2019.01.068.

(35) Han, Z.-J.; Yabuuchi, N.; Shimomura, K.; Murase, M.; Yui, H.; Komaba, S. HighCapacity Si-Graphite Composite Electrodes with a Self-Formed Porous Structure by a Partially Neutralized Polyacrylate for Li-Ion Batteries. Energy Environ. Sci. 2012, 5 (10), 9014. https://doi.org/10.1039/c2ee22292b.

(36) Rodrigues, M.-T. F.; Trask, S. E.; Shkrob, I. A.; Abraham, D. P. Quantifying Gas Generation from Slurries Used in Fabrication of Si-Containing Electrodes for LithiumIon Cells. J. Power Sources 2018, 395, 289-294. https://doi.org/10.1016/j.jpowsour.2018.05.071. 
(37) Hays, K. A.; Key, B.; Li, J.; Wood, D. L.; Veith, G. M. Si Oxidation and $\mathrm{H}_{2}$ Gassing During Aqueous Slurry Preparation for Li-Ion Battery Anodes. J. Phys. Chem. C 2018, 122 (18), 9746-9754. https://doi.org/10.1021/acs.jpcc.8b01062.

(38) Han, Z.-J.; Yamagiwa, K.; Yabuuchi, N.; Son, J.-Y.; Cui, Y.-T.; Oji, H.; Kogure, A.; Harada, T.; Ishikawa, S.; Aoki, Y.; Komaba, S. Electrochemical Lithiation Performance and Characterization of Silicon-Graphite Composites with Lithium, Sodium, Potassium, and Ammonium Polyacrylate Binders. Phys. Chem. Chem. Phys. 2015, 17 (5), 37833795. https://doi.org/10.1039/C4CP04939J.

(39) Komaba, S.; Ozeki, T.; Yabuuchi, N.; Shimomura, K. Polyacrylate as Functional Binder for Silicon and Graphite Composite Electrode in Lithium-Ion Batteries. Electrochemistry 2011, 79 (1), 6-9. https://doi.org/10.5796/electrochemistry.79.6.

(40) Komaba, S.; Okushi, K.; Ozeki, T.; Yui, H.; Katayama, Y.; Miura, T.; Saito, T.; Groult, H. Polyacrylate Modifier for Graphite Anode of Lithium-Ion Batteries. Electrochem. Solid-State Lett. 2009, 12 (5), A107. https://doi.org/10.1149/1.3086262.

(41) Nguyen, C. C.; Yoon, T.; Seo, D. M.; Guduru, P.; Lucht, B. L. Systematic Investigation of Binders for Silicon Anodes: Interactions of Binder with Silicon Particles and Electrolytes and Effects of Binders on Solid Electrolyte Interphase Formation. ACS Appl. Mater. Interfaces 2016, 8 (19), 12211-12220. https://doi.org/10.1021/acsami.6b03357.

(42) Burdette-Trofimov, M. K.; Armstrong, B. L.; Nelson Weker, J.; Rogers, A. M.; Yang, G.; Self, E. C.; Armstrong, R. R.; Nanda, J.; Veith, G. M. Direct Measure of Electrode Spatial Heterogeneity: Influence of Processing Conditions on Anode Architecture and Performance. ACS Appl. Mater. Interfaces 2020, 12 (50), 55954-55970. https://doi.org/10.1021/acsami.0c17019.

(43) Hays, K. A.; Armstrong, B.; Veith, G. M. Ending the Chase for a Perfect Binder: Role of Surface Chemistry Variation and Its Influence on Silicon Anodes. ChemElectroChem 2020, 7 (18), 3790-3797. https://doi.org/10.1002/celc.202001066.

(44) Chartrel, T.; Ndour, M.; Bonnet, V.; Cavalaglio, S.; Aymard, L.; Dolhem, F.; Monconduit, L.; Bonnet, J.-P. Revisiting and Improving the Preparation of Silicon-Based Electrodes for Lithium-Ion Batteries: Ball Milling Impact on Poly(Acrylic Acid) Polymer Binders. Mater. Chem. Front. 2019, 3 (5), 881-891.

https://doi.org/10.1039/C8QM00660A.

(45) Delpuech, N.; Dupré, N.; Mazouzi, D.; Gaubicher, J.; Moreau, P.; Bridel, J. S.; Guyomard, D.; Lestriez, B. Correlation between Irreversible Capacity and Electrolyte Solvents Degradation Probed by NMR in Si-Based Negative Electrode of Li-Ion Cell. Electrochem. Commun. 2013, 33, 72-75. https://doi.org/10.1016/j.elecom.2013.05.001.

(46) Oumellal, Y.; Delpuech, N.; Mazouzi, D.; Dupré, N.; Gaubicher, J.; Moreau, P.; Soudan, P.; Lestriez, B.; Guyomard, D. The Failure Mechanism of Nano-Sized Si-Based Negative Electrodes for Lithium Ion Batteries. J. Mater. Chem. 2011, 21 (17), 6201. https://doi.org/10.1039/c1jm10213c.

(47) Petibon, R.; Xia, J.; Ma, L.; Bauer, M. K. G.; Nelson, K. J.; Dahn, J. R. Electrolyte System for High Voltage Li-Ion Cells. J. Electrochem. Soc. 2016, 163 (13), A2571A2578. https://doi.org/10.1149/2.0321613jes.

(48) Ehteshami, N.; Ibing, L.; Stolz, L.; Winter, M.; Paillard, E. Ethylene Carbonate-Free Electrolytes for Li-Ion Battery: Study of the Solid Electrolyte Interphases Formed on Graphite Anodes. J. Power Sources 2020, 451, 227804. https://doi.org/10.1016/j.jpowsour.2020.227804. 
(49) Home | dmfit - D.Massiot - NMR@CEMHTI CNRS UPR3079 Orléans France https://nmr.cemhti.cnrs-orleans.fr/dmfit/default.aspx (accessed Nov 17, 2020).

(50) Cuisinier, M.; Martin, J.-F.; Moreau, P.; Epicier, T.; Kanno, R.; Guyomard, D.; Dupré, N. Quantitative MAS NMR Characterization of the LiMn1/2Ni1/2O2 Electrode/Electrolyte Interphase. Solid-State NMR Mater. Energy Storage Convers. 2012, 42, 51-61. https://doi.org/10.1016/j.ssnmr.2011.09.001.

(51) Hawley, W. B.; Li, J. Electrode Manufacturing for Lithium-Ion Batteries-Analysis of Current and next Generation Processing. J. Energy Storage 2019, 25, 100862. https://doi.org/10.1016/j.est.2019.100862.

(52) Swift, T.; Swanson, L.; Geoghegan, M.; Rimmer, S. The PH-Responsive Behaviour of Poly(Acrylic Acid) in Aqueous Solution Is Dependent on Molar Mass. Soft Matter 2016, 12 (9), 2542-2549. https://doi.org/10.1039/C5SM02693H.

(53) Liu, L.; Gonzalez-Olivares, M. A.; Bai, H.; Yi, H.; Song, S. Colloidal Stability of Silica and Graphite in Aqueous Suspensions. Chem. Phys. 2019, 525, 110405. https://doi.org/10.1016/j.chemphys.2019.110405.

(54) Nguyen, B. P. N.; Chazelle, S.; Cerbelaud, M.; Porcher, W.; Lestriez, B. Manufacturing of Industry-Relevant Silicon Negative Composite Electrodes for Lithium Ion-Cells. $J$. Power Sources 2014, 262, 112-122. https://doi.org/10.1016/j.jpowsour.2014.03.119.

(55) Tadros, Th. F. Solid/Liquid Dispersions. Edited by Th. F. Tadros. Academic Press, London 1987. Angew. Chem. 1989, 101 (4), 545-546. https://doi.org/10.1002/ange.19891010457.

(56) Gattinoni, C.; Michaelides, A. Atomistic Details of Oxide Surfaces and Surface Oxidation: The Example of Copper and Its Oxides. Surf. Sci. Rep. 2015, 70 (3), 424-447. https://doi.org/10.1016/j.surfrep.2015.07.001.

(57) Gil, H.; Leygraf, C. Initial Atmospheric Corrosion of Copper Induced by Carboxylic Acids. J. Electrochem. Soc. 2007, 154 (11), C611. https://doi.org/10.1149/1.2773627.

(58) Mazouzi, D.; Grissa, R.; Paris, M.; Karkar, Z.; Huet, L.; Guyomard, D.; Roué, L.; Devic, T.; Lestriez, B. CMC-Citric Acid Cu(II) Cross-Linked Binder Approach to Improve the Electrochemical Performance of Si-Based Electrodes. Electrochimica Acta 2019, 304, 495-504. https://doi.org/10.1016/j.electacta.2019.03.026.

(59) Delpuech, N.; Mazouzi, D.; Dupré, N.; Moreau, P.; Cerbelaud, M.; Bridel, J. S.; Badot, J.-C.; De Vito, E.; Guyomard, D.; Lestriez, B.; Humbert, B. Critical Role of Silicon Nanoparticles Surface on Lithium Cell Electrochemical Performance Analyzed by FTIR, Raman, EELS, XPS, NMR, and BDS Spectroscopies. J. Phys. Chem. C 2014, 118 (31), 17318-17331. https://doi.org/10.1021/jp503949y.

(60) Dedryvère, R.; Laruelle, S.; Grugeon, S.; Gireaud, L.; Tarascon, J.-M.; Gonbeau, D. XPS Identification of the Organic and Inorganic Components of the Electrode/Electrolyte Interface Formed on a Metallic Cathode. J. Electrochem. Soc. 2005, 152 (4), A689. https://doi.org/10.1149/1.1861994.

(61) Font, F.; Protas, B.; Richardson, G.; Foster, J. M. Binder Migration during Drying of Lithium-Ion Battery Electrodes: Modelling and Comparison to Experiment. J. Power Sources 2018, 393, 177-185. https://doi.org/10.1016/j.jpowsour.2018.04.097.

(62) Jaiser, S.; Müller, M.; Baunach, M.; Bauer, W.; Scharfer, P.; Schabel, W. Investigation of Film Solidification and Binder Migration during Drying of Li-Ion Battery Anodes. J. Power Sources 2016, 318, 210-219. https://doi.org/10.1016/j.jpowsour.2016.04.018. 
(63) Kwon, T.; Choi, J. W.; Coskun, A. The Emerging Era of Supramolecular Polymeric Binders in Silicon Anodes. Chem. Soc. Rev. 2018, 47 (6), 2145-2164. https://doi.org/10.1039/C7CS00858A.

(64) Lim, S.; Ahn, K. H.; Yamamura, M. Latex Migration in Battery Slurries during Drying. Langmuir 2013, 29 (26), 8233-8244. https://doi.org/10.1021/la4013685.

(65) Yoo, M.; Frank, C. W.; Mori, S.; Yamaguchi, S. Effect of Poly(Vinylidene Fluoride) Binder Crystallinity and Graphite Structure on the Mechanical Strength of the Composite Anode in a Lithium Ion Battery. Polymer 2003, 44 (15), 4197-4204. https://doi.org/10.1016/S0032-3861(03)00364-1.

(66) Yao, K. P. C.; Okasinski, J. S.; Kalaga, K.; Almer, J. D.; Abraham, D. P. Operando Quantification of (De)Lithiation Behavior of Silicon-Graphite Blended Electrodes for Lithium-Ion Batteries. Adv. Energy Mater. 2019, 9 (8), 1803380. https://doi.org/10.1002/aenm.201803380.

(67) Gauthier, M.; Mazouzi, D.; Reyter, D.; Lestriez, B.; Moreau, P.; Guyomard, D.; Roué, L. A Low-Cost and High Performance Ball-Milled Si-Based Negative Electrode for HighEnergy Li-Ion Batteries. Energy Environ. Sci. 2013, 6 (7), 2145. https://doi.org/10.1039/c3ee41318g.

(68) Key, B.; Morcrette, M.; Tarascon, J.-M.; Grey, C. P. Pair Distribution Function Analysis and Solid State NMR Studies of Silicon Electrodes for Lithium Ion Batteries: Understanding the (De)Lithiation Mechanisms. J. Am. Chem. Soc. 2011, 133 (3), 503512. https://doi.org/10.1021/ja108085d.

(69) Jin, Y.; Zhu, B.; Lu, Z.; Liu, N.; Zhu, J. Challenges and Recent Progress in the Development of Si Anodes for Lithium-Ion Battery. Adv. Energy Mater. 2017, 7 (23), 1700715. https://doi.org/10.1002/aenm.201700715.

(70) Peled, E.; Menkin, S. Review-SEI: Past, Present and Future. J. Electrochem. Soc. 2017, 164 (7), A1703-A1719. https://doi.org/10.1149/2.1441707jes.

(71) Jow, T. R.; Allen, J.; Marx, M.; Nechev, K.; Deveney, B.; Rickman, S. (Invited) Electrolytes, SEI and Charge Discharge Kinetics in Li-Ion Batteries. ECS Trans. 2019, 25 (36), 3-12. https://doi.org/10.1149/1.3393833.

(72) Vanpeene, V.; Soucy, P.; Xiong, J.; Dupre, N.; Lestriez, B.; Roué, L. Sequential Focused Ion Beam Scanning Electron Microscopy Analyses for Monitoring Cycled-Induced Morphological Evolution in Battery Composite Electrodes. Silicon-Graphite Electrode as Exemplary Case. J. Power Sources 2021, 12.

(73) Sourice, J.; Quinsac, A.; Leconte, Y.; Sublemontier, O.; Porcher, W.; Haon, C.; Bordes, A.; De Vito, E.; Boulineau, A.; Jouanneau Si Larbi, S.; Herlin-Boime, N.; Reynaud, C. One-Step Synthesis of Si@C Nanoparticles by Laser Pyrolysis: High-Capacity Anode Material for Lithium-Ion Batteries. ACS Appl. Mater. Interfaces 2015, 7 (12), 66376644. https://doi.org/10.1021/am5089742.

(74) Liu, X.; Zhou, J.; Xu, Z.; Wang, Y. Atomic Thermodynamics and Microkinetics of the Reduction Mechanism of Electrolyte Additives to Facilitate the Formation of Solid Electrolyte Interphases in Lithium-Ion Batteries. RSC Adv. 2020, 10 (28), 16302-16312. https://doi.org/10.1039/D0RA01412E.

(75) Shen, B. H.; Veith, G. M.; Tenhaeff, W. E. Silicon Surface Tethered Polymer as Artificial Solid Electrolyte Interface. Sci. Rep. 2018, 8 (1), 11549. https://doi.org/10.1038/s41598-018-30000-z. 
(76) Browning, K. L.; Sacci, R. L.; Doucet, M.; Browning, J. F.; Kim, J. R.; Veith, G. M. The Study of the Binder Polyacrylic Acid and Its Role in Concomitant Solid- Electrolyte Interphase Formation on Silicon Anodes. ACS Appl. Mater. Interfaces 2020, 6.

(77) Lee, J.; Kim, Y.-J.; Jin, H. S.; Noh, H.; Kwack, H.; Chu, H.; Ye, F.; Lee, H.; Kim, H.-T. Tuning Two Interfaces with Fluoroethylene Carbonate Electrolytes for HighPerformance Li/LCO Batteries. ACS Omega 2019, 4 (2), 3220-3227. https://doi.org/10.1021/acsomega.8b03022.

(78) Vanpeene, V.; Soucy, P.; Xiong, J.; Dupre, N.; Lestriez, B.; Roué, L. Sequential Focused Ion Beam Scanning Electron Microscopy Analyses for Monitoring Cycled-Induced Morphological Evolution in Battery Composite Electrodes. Silicon-Graphite Electrode as Exemplary Case. J. Power Sources submitted.

(79) Dupré, N.; Moreau, P.; De Vito, E.; Quazuguel, L.; Boniface, M.; Bordes, A.; Rudisch, C.; Bayle-Guillemaud, P.; Guyomard, D. Multiprobe Study of the Solid Electrolyte Interphase on Silicon-Based Electrodes in Full-Cell Configuration. Chem. Mater. 2016, 28 (8), 2557-2572. https://doi.org/10.1021/acs.chemmater.5b04461.

(80) Philippe, B.; Dedryvère, R.; Allouche, J.; Lindgren, F.; Gorgoi, M.; Rensmo, H.; Gonbeau, D.; Edström, K. Nanosilicon Electrodes for Lithium-Ion Batteries: Interfacial Mechanisms Studied by Hard and Soft X-Ray Photoelectron Spectroscopy. Chem. Mater. 2012, 24 (6), 1107-1115. https://doi.org/10.1021/cm2034195.

(81) Meyer, B. M.; Leifer, N.; Sakamoto, S.; Greenbaum, S. G.; Grey, C. P. High Field Multinuclear NMR Investigation of the SEI Layer in Lithium Rechargeable Batteries. Electrochem. Solid-State Lett. 2005, 8 (3), A145. https://doi.org/10.1149/1.1854117.

(82) Scherf, L. M.; Karttunen, A. J.; Pecher, O.; Magusin, P. C. M. M.; Grey, C. P.; Fässler, T. F. [Ge ${ }_{2}{ }^{4-}$ Dumbbells with Very Short Ge-Ge Distances in the Zintl Phase Li 3 $\mathrm{NaGe}_{2}$ : A Solid-State Equivalent to Molecular $\mathrm{O}_{2}$. Angew. Chem. Int. Ed. 2016, 55 (3), 1075-1079. https://doi.org/10.1002/anie.201508044.

(83) Key, B.; Bhattacharyya, R.; Morcrette, M.; Seznéc, V.; Tarascon, J.-M.; Grey, C. P. Real-Time NMR Investigations of Structural Changes in Silicon Electrodes for LithiumIon Batteries. J. Am. Chem. Soc. 2009, 131 (26), 9239-9249. https://doi.org/10.1021/ja8086278.

(84) Lataste, E.; Legein, C.; Body, M.; Buzaré, J.-Y.; Tressaud, A.; Demourgues, A. Highly Fluorinated Silica Obtained by Direct $F_{2}$-Gas Fluorination: Stability and Unprecedented Fluorosilicate Species Revealed by Solid State NMR Investigations. J. Phys. Chem. C 2009, 113 (43), 18652-18660. https://doi.org/10.1021/jp9087628.

(85) Philippe, B.; Edstro, K. Role of the LiPF6 Salt for the Long-Term Stability of Silicon Electrodes in Li-Ion Batteries - A Photoelectron Spectroscopy Study. Chem Mater 2013, 11.

(86) Bareño, J.; Shkrob, I. A.; Gilbert, J. A.; Klett, M.; Abraham, D. P. Capacity Fade and Its Mitigation in Li-Ion Cells with Silicon-Graphite Electrodes. J. Phys. Chem. C 2017, 121 (38), 20640-20649. https://doi.org/10.1021/acs.jpcc.7b06118.

(87) Schroder, K.; Alvarado, J.; Yersak, T. A.; Li, J.; Dudney, N.; Webb, L. J.; Meng, Y. S.; Stevenson, K. J. The Effect of Fluoroethylene Carbonate as an Additive on the Solid Electrolyte Interphase on Silicon Lithium-Ion Electrodes. Chem Mater 2015, 12.

(88) Lee, J.-H.; Choi, Y.-M.; Paik, U.; Park, J.-G. The Effect of Carboxymethyl Cellulose Swelling on the Stability of Natural Graphite Particulates in an Aqueous Medium for 
Lithium Ion Battery Anodes. J. Electroceramics 2006, 17 (2), 657-660.

https://doi.org/10.1007/s10832-006-8975-4.

(89) Radvanyi, E.; Van Havenbergh, K.; Porcher, W.; Jouanneau, S.; Bridel, J.-S.; Put, S.; Franger, S. Study and Modeling of the Solid Electrolyte Interphase Behavior on NanoSilicon Anodes by Electrochemical Impedance Spectroscopy. Electrochimica Acta 2014, 137, 751-757. https://doi.org/10.1016/j.electacta.2014.06.069.

(90) Wetjen, M.; Solchenbach, S.; Pritzl, D.; Hou, J.; Tileli, V.; Gasteiger, H. A. Morphological Changes of Silicon Nanoparticles and the Influence of Cutoff Potentials in Silicon-Graphite Electrodes. J. Electrochem. Soc. 2018, 165 (7), A1503-A1514. https://doi.org/10.1149/2.1261807jes.

(91) Ruffo, R.; Hong, S. S.; Chan, C. K.; Huggins, R. A.; Cui, Y. Impedance Analysis of Silicon Nanowire Lithium Ion Battery Anodes. J. Phys. Chem. C 2009, 113 (26), 1139011398. https://doi.org/10.1021/jp901594g.

(92) Yan, Z.; Wei, C.; Obrovac, M. N. Understanding Interfacial Impedance Growth in Porous Electrodes Containing Blended Active Materials. J. Power Sources 2019, 438, 226955. https://doi.org/10.1016/j.jpowsour.2019.226955.

(93) Gan, L.; Guo, H.; Wang, Z.; Li, X.; Peng, W.; Wang, J.; Huang, S.; Su, M. A Facile Synthesis of Graphite/Silicon/Graphene Spherical Composite Anode for Lithium-Ion Batteries. Electrochimica Acta 2013, 104, 117-123. https://doi.org/10.1016/j.electacta.2013.04.083.

(94) Zheng, Y.; Seifert, H. J.; Shi, H.; Zhang, Y.; Kübel, C.; Pfleging, W. 3D Silicon/Graphite Composite Electrodes for High-Energy Lithium-Ion Batteries. Electrochimica Acta 2019, 317, 502-508. https://doi.org/10.1016/j.electacta.2019.05.064.

(95) Zeng, Z.; Zeng, Q.; Liu, N.; Oganov, A. R.; Zeng, Q.; Cui, Y.; Mao, W. L. A Novel Phase of Li15Si4 Synthesized under Pressure. Adv. Energy Mater. 2015, 5 (12), 1500214. https://doi.org/10.1002/aenm.201500214.

(96) Veith, G. M.; Doucet, M.; Sacci, R. L.; Vacaliuc, B.; Baldwin, J. K.; Browning, J. F. Determination of the Solid Electrolyte Interphase Structure Grown on a Silicon Electrode Using a Fluoroethylene Carbonate Additive. Sci. Rep. 2017, 7 (1), 6326. https://doi.org/10.1038/s41598-017-06555-8.

(97) Kitz, P. G.; Lacey, M. J.; Novák, P.; Berg, E. J. Operando Investigation of the Solid Electrolyte Interphase Mechanical and Transport Properties Formed from Vinylene Carbonate and Fluoroethylene Carbonate. J. Power Sources 2020, 477, 228567. https://doi.org/10.1016/j.jpowsour.2020.228567. 

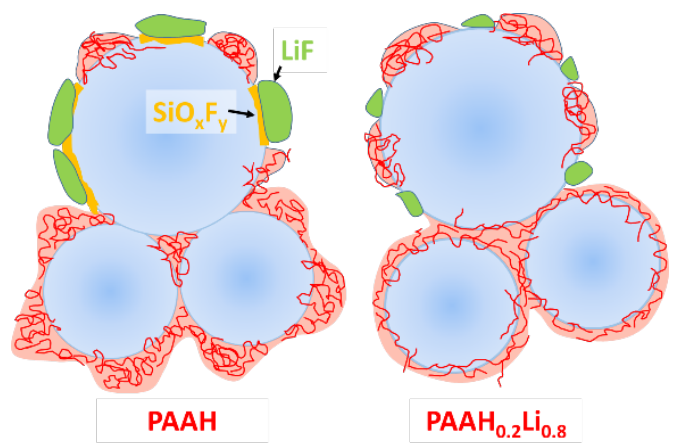

For table of content only 